\title{
"Hijos de los jesuitas” o ¿Hijos de su propio pasado?
}

"Children of the jesuits" or children of their past?

Kate Ford ${ }^{*}$

Resumen: Los cronistas jesuitas y, más tarde, los antropólogos de los siglos XX y XXI registraron las técnicas indígenas para asegurar la sobrevivencia en la época antes de la evangelización. Este artículo argumenta que las siguientes técnicas continuaron jugando un papel en la misión: las habilidades cinegéticas, el respeto a lo sobrenatural y a los ritos que lo sostenían, la creencia en el poder de sustancias sagradas, la modificación del cuerpo para que el capricho de los espíritus se desviara, y la costumbre de hacer marcas en sitios numinosos. Concluye que los templos pintados de la misión de aquel entonces reflejaron tanto el intento jesuita de disfrazar carencias percibidas en los edificios como el intento indígena de protegerlos contra el daño que se consideraba ser causado por espíritus malignos.

Palabras clave: Chiquitos, caza, ritos, modificación del cuerpo, arte rupestre

Summary: This paper argues that pre-evangelisation indigenous survival techniques noted in both contemporaneous Jesuit sources and in subsequent 20th- and 21stcentury anthropological research continued to be employed in the mission to the Chiquitos. These concerned hunting, respect towards the supernatural combined with ritual attendant on that respect, a belief in the power of potent substances, modifying the body to deflect supernatural caprice, and marking numinous sites. It concludes that the painted churches reflected both Jesuit attempts to disguise the churches' perceived deficiencies and indigenous attempts to protect them from harm.

Keywords: Chiquitos, hunting, ritual, body-modification, rock art

\footnotetext{
${ }^{*} \mathrm{PhD}$ de la Universidad de Essex, Inglaterra.

E-mail: katefordis@gmail.com
} 
Recibido: 6 de setiembre de 2016

Evaluado: 8 de noviembre de 2016 


\section{1. "Modus noster procendi"}

Este artículo coteja fuentes jesuíticas del siglo XVIII, información adquirida desde que se inició la restauración de los conjuntos misionales de los años setenta del siglo XX, e investigaciones antropológicas y arqueológicas de los siglos XX y XXI. A pesar de que hay estudios académicos sobre la historia de la misión ${ }^{1}$, el arte y la arquitectura misional $^{2}$ y estudios antropológicos de los indígenas de la región ${ }^{3}$, falta una yuxtaposición de las investigaciones de los historiadores, los historiadores del arte y los antropólogos que clarifique ciertos aspectos del esfuerzo misional que, en la opinión popular, se tiende a atribuir a los jesuitas. Sostengo que las evidencias antropológicas y arqueológicas muestren que los autodenominados "hijos de nuestros misioneros ", 4 seguían tanto la práctica de sus antepasados como la de los jesuitas.

En primer lugar se dan dos ejemplos de cómo emplearon los indígenas sus propias habilidades y creencias al servicio de los jesuitas.

\section{1 "Cazas espirituales", la búsqueda de almas}

Ya en el año 1709, 18 años después de la fundación de la misión, se hizo patente la carencia de misioneros en la misión de los Chiquitos. Una carta del general Miguel Ángel Tamburini, al provincial de la Provincia del Paraguay, Blas de Silva, le aconsejó que se agruparan en dos, las cuatro misiones de entonces (San Javier, San Rafael, San José y San Juan Bautista -aunque Concepción se fundó en el año 1699, ésta había sido disuelta en el año 1704 y no se restableció hasta el año $1709^{5}$-). Cada una de las misiones colectivas iba a tener dos sacerdotes residentes y los cuatro misioneros que entonces quedaban, se iban a emplear como "misioneros volantes", que irían a la región de las tribus colindantes, haciendo "sacras correrías" para recoger más almas. Luego, conforme con la tradición en otras misiones, hizo otra sugerencia:

"[L]os padres que están de asiento podrán instruir con más especialidad a algunos indios más capaces, así en la doctrina cristiana de forma que la puedan enseñar, como en el modo de administrar el santo bautismo. Estos podrán enviarse a los pueblos que no tienen padres". 6

La unión de las cuatro misiones no se realizó pero las "sacras correrías", usando indígenas en el proceso evangelizador, venían a ser una parte fundamental de la metodología de la misión de los Chiquitos. En su Relato, publicado después de la expulsión, el misionero Julián Knogler hizo eco de la frase de Tamburini al describirlos como "cazas espirituales".

\footnotetext{
${ }^{1}$ Menacho, 1996. Tomichá, 2002 y 2008. Combès, 2010. Matienzo et al., 2011.

${ }^{2}$ Parejas Moreno y Suárez Salas, 1992. Querejazu, 1995 y 2000. Diez Gálvez, 2006. Kühne, 2008.

${ }^{3}$ Riester y Fischerman, 1976. Fischerman y Quiroaga, 1996. Strack, 1992. Balza Alarcón, 2001. Bórmida y Califano, 2003. Combès 2009.

${ }^{4}$ Fernández, 1994: 207. Fernández cita la respuesta de un miembro de un "caza espiritual" a la pregunta del capitán de una banda de Mamelucos: "Respondió que eran hijos de nuestros misioneros (esta es la frase que usan ellos con los que les han reducido a la fe)"

${ }^{5}$ Groesbeck, 2012: 25.

${ }^{6}$ Matienzo, 2011: 85.

${ }^{7}$ Knogler, 1979: 164.
}

49 Kate Ford. "Hijos de los jesuitas" o ¿Hijos de su propio pasado?... 47-79. 
Las expediciones emprendidas por el misionero Lucas Caballero a principios del siglo XVIII, registradas en su Relación y "Diario", parecen más bien haber sido más cercanas a cruzadas que a cacerías. Aunque los jesuitas censuraron las actividades de los maloquistas cruceños y los mamelucos brasileños, en esa época se consideraba el enemigo más peligroso al diablo y el P. Caballero atribuyó sus "éxitos" (en cuanto al número de conversos) a los "maravillas y milagros" de los que habló en el "Diario". ${ }^{8}$ El P. Caballero esperaba que sus compañeros, a quienes dedicó su obra, entenderían "cuán ruin soy", y también entenderían que sus logros se los debió sólo a Dios, ${ }^{9}$ pero de hecho, el papel crucial de sus intérpretes se hace evidente al lector. En una ocasión, escribió:

"Llevaba un muchacho de los mismos pueblos, que dos años había [sic] le había bautizado; al cual mandé se adelantase para darles a sus parientes razón de mi venida". ${ }^{10}$

El número de personas de esta expedición aumentó con un grupo de los tapacuras antes de avanzar hacia el territorio de los quimamacas. Allí el mismo joven -u otro- fue enviado por delante y les explicó a los quimamacas muy convincentemente que el daño causado a la cruz levantada antes en el asentamiento, había resultado en muertes entre la gente, lo cual los tranquilizó, "haciéndolo no como cristiano nuevo, sino como ángel". "Luego el grupo pasó al territorio de los paunacas, donde al lector de hoy le parece aún claro la importancia de los intérpretes:

"Les saludé, les hablé, y todos hablábamos, y nadie nos entendíamos, porque hablábamos en tres lenguas distintas, por concurrir gentiles de tres naciones. Parecía la confusión de Babilonia; yo hablaba las dos lenguas, pero no sabía la tercera. No obstante, con algunas palabras que la tarde antes había escrito de los paunacas, mezclando otras de los manasicas y las acciones, les conté cierta historia que les asustó y dio miedo, mostrando bien que me habían entendido". ${ }^{12}$

El P. Juan Bautista de Zea, el visitador de la misión, visitó San José en 1708. Propició visitas de dos grupos de cristianos nuevos a dos grupos indígenas fugitivos encontrados el año anterior. Como dice Tomichá Charupá, esto señala la fecha de 1707 para las primeras expediciones no supervisadas, el año en el que un grupo de neófitos tabicas y taus fue enviado en busca de unos miembros desaparecidos de la misión de San Rafael. ${ }^{13}$ Años más tarde el mismo P. Zea evitó ser asesinado intempestivamente por las manos de los cucutades, gracias a la intervención de "un $\mathrm{ca}$ tecúmeno de gran autoridad" (es de suponer que éste hablaba zamuco, el idioma de los cucutades) que les explicó que no deberían matar al P. Zea porque sólo quería hacer lo bueno, no lo malo. ${ }^{14}$

\footnotetext{
${ }^{8}$ Caballero, 2011: 64.

${ }^{9}$ Ibid.: 46.

${ }^{10}$ Ibid.: 74.

${ }^{11}$ Ibid.: 77.

${ }^{12}$ Ibid.: 79.

${ }^{13}$ Tomichá Charupa, 2002: 537.

${ }^{14}$ Matienzo, 2011: 108.
} 
Entre los años 1707 a 1766, al menos una expedición en busca de almas salía de cada pueblo misional casi todos los años. ${ }^{15}$ A veces las expediciones eran terminadas debido a indígenas hostiles, o a la falta de agua en la ruta; no obstante a veces regresaban cargados de "botín", es decir nuevas almas, como el provincial informó en la Anua de $1730-1734 .{ }^{16}$ De vez en cuando volvían manivacíos, o con solo uno o dos indígenas. En la Anua de 1751-1756 fue anotado que: "las más de las veces, ellos solos [los "indios"], yéndose a los infieles". 17

Aunque los miembros de las primeras expediciones evangelizadoras fueron de la etnia chiquita, la composición de una fuerza expedicionaria cambió durante el período misional, según la demografía de cada misión particular: por ejemplo, las excursiones que salían de San Ignacio de Zamucos, fundado para los zamucos de la región, eran proveedores de personal zamuco. ${ }^{18}$ El P. Pedro Lozano, el historiador de la Provincia paraguayana del siglo XVIII, transmitió el contenido de una carta del misionero P. Diego Contreras al procurador de la provincia el P. Sebastián de San Martín. En su carta el P. Contreras había elogiado no solo el fervor apostólico de gente de otras etnias que vivían hasta ayer "en los montes como unos brutos", 19 sino también el de los chiquitos, "la flor de esta cristiandad". ${ }^{20}$ El entusiasmo sentido sobre todo por los chiquitos evangelizadores fue atribuido a la idea romántica de que había algo del sacramento bautismal mismo que les había dado no solo una nueva fe sino también un gran fervor proselitista para ganar neófitos. Esto se lo explicó el P. Esteban Palozzi en el año 1763 al gobernador de Santa Cruz en su Informe, mediante las siguientes palabras:

"[c]on el santo bautismo depusieron los chiquitos su barbarie y ferocidad [ . . .] y se vistieron de la mansedumbre cristiana, y mudados en misioneros acompañaron a los padres para la reducción de las naciones confinantes ". ${ }^{21}$

En la Anua de 1757-1762 se informó:

"Las misiones de los chiquitos son tan apreciables porque los nuevos cristianos aprenden de nuestros misioneros el espíritu apostólico, y un ardiente celo de convertir a los infieles a la verdadera religión. Pues desean ellos, y piden, ser encargados de las excursiones a los bárbaros, parientes suyos o amigos, y hasta a veces enemigos, distantes 100 leguas o más. Encontrando ellos resistencia, les echan miedo con las armas sin hacerles daño, y así los sujetan. A los así sujetados llevan ellos a los pueblos y los alojan caritativamente en sus propias casas. Les mantienen allí, les amansan y les instruyen en la doctrina cristiana. ",22

\footnotetext{
15 Ibid.: 165 La Anua de 1730-1734 apuntó “excursiones annuales muy largas y difíciles”; véase tambíen listas de excursiones en el Cap 6, Tomichá Charupa, 2002.

${ }^{16}$ Ibid.: 160 "con su botín de 162 almas".

${ }^{17}$ Ibid.: 338.

${ }^{18}$ Ibid.: 191.

${ }^{19}$ Ibid.: 200.

${ }^{20}$ Ibid.: 199.

${ }^{21}$ Ibid.: 405.

${ }^{22}$ Ibid.: 363.
} 
Hay que señalar que los jesuitas eran partidarios de los chiquitos, al ser los primeros indígenas reducidos de la región; además la gente "de las naciones confinantes” les temían por lo que el P. Fernández describió como con su ánimo valeroso: "asaltan [a sus enemigos] sin otro motivo más que por quitarles algún pedazo de hierro o por alcanzar fama y nombre de valerosos en la guerra". 23

En mi opinión, lo que contribuyó al fervor misional de los chiquitos de aquel entonces fue la semejanza de este proceso evangelizador a las costumbres cinegéticas de antaño. Las cazas de la época pre-jesuita eran también anuales y, duraban dos o tres meses. Los participantes indígenas de una "caza espiritual" se preparaban para la tarea pintándose el rostro de rojo, ${ }^{24}$ aunque el P. Knogler registró en el Relato que a los habitantes de una misión no se les permitía comulgar en la iglesia de una misión "adornos [de] [. . .] pinturas". ${ }^{25}$ Entre los ayoréodes del sureste de la zona y los guaycurúes del este, rojo era el color de la pintura del cuerpo para celebraciones; ${ }^{26}$ así podemos entender que una expedición era considerada una ocasión feliz. El P. Fernández tomó nota sobre la costumbre pre-misional que consistía en que un pretendiente depositaba una cantidad impresionante de presas fuera de la choza del padre de la prometida ${ }^{27}$ (y Brotherston [1992] describió a los héroes de leyendas suramericanas que realizaban tareas para el padre de la mujer deseada ${ }^{28}$ ). Se podría sostener que, al traer un "botín" de almas, los cazadores misionales esperaban ganar el favor del [P]adre (Dios) o de los padres jesuitas (se referían a sus mismos como hijos de los jesuitas, como puntualizo a principios de este artículo). La atestiguada devoción misional a la Virgen, tal vez fortalezca esta analogía en la confusión de una conversión rápida y superficial, Dios, Padre de todos, fue considerado el Padre también de la Virgen, mientras que, desconcertantemente, "Padre mío Jesucristo" fue la entidad a quien se dirigieron dos cantos litúrgicos. ${ }^{29}$ En su memorial de 1703 el P. Burgés contó cómo, antes de la llegada de los jesuitas, "[a] los que apressan [sic] en sus guerras tratan sin más diferencia que la que usan entre sí mismos, y muchas vezes [sic] los casan con sus mismos hijas "; ${ }^{30}$ los habitantes de una misión albergaban a los recién llegados en sus casas inicialmente, como se plantea la Anua de 1757-1762 citada arriba.

Una técnica de la caza anotada por el P. Knogler en el Relato, era arrasar un área circular de matorral alrededor de un abrevadero, de manera que los cazadores pudieran levantar la presa antes de matarla en campo abierto. ${ }^{31}$ Este se reflejó por una técnica misional que también anotó, en la que los "cazadores" rodeaban un asentamiento indígena con el objeto de que nadie pudiera huir: "Ya a una distancia de dos jornadas del presumible paradero de los bárbaros formamos un círculo para cercar

\footnotetext{
${ }^{23}$ Fernández, 1994: 37.

${ }^{24}$ Diez Gálves, 2006: 382, nota de pie 9.

${ }^{25}$ Knogler, 1979: 176 "sin los adornos, como plumas o pinturas, que usan comúnmente"

${ }^{26}$ Bórmida y Califano, 2003: 93 (Ayoréode); Sánchez Labrador, 1910: 308 (Guaycuru).

${ }^{27}$ Fernández, 1994. También citado por Balza Alarcón, 2001: 106.

${ }^{28}$ Brotherston, 1992: 267.

${ }^{29}$ Galeote Tormo, 1996: 291.

${ }^{30}$ Burgés, 2008: 92.

${ }^{31}$ Knogler, 1979: 145.
} 
a los infieles y evitar que escapen ${ }^{, 32}$. El mismo método había sido descrito por el P. Contreras 40 años antes en relación a una excursión de San Rafael del año $1730{ }^{33} \mathrm{El}$ aflojamiento del agarre diabólico en el Oriente -como lo percibían los misioneros- se debió menos a los "maravillas y milagros" a cuales lo atribuyó el P. Caballero que a los intérpretes, intermediarios y cazadores expertos indígenas.

\subsection{Ritual litúrgico}

Otro elemento de la vida misional, teóricamente bajo el control de los jesuitas, era el ritual de la iglesia. Los miembros indígenas de una misión tomaban parte en su rito en una manera que reflejaba a sus tradiciones y creencias de igual modo que sus costumbres de la caza guiaban la búsqueda de almas. El ritual litúrgico de la misión siguió la práctica pre-misional de comunicación con lo sobrenatural a través de ofrendas y figuras autoritarias.

Durkheim y Mauss señalaron que un elemento común de los mitos de la creación del mundo es la inversión del orden social que pertenece a una sociedad: "los principios de la clasificación social existente son inoperantes o son desacatados". ${ }^{34}$ Décadas después, Sá y Brotherston relacionan este punto específicamente con las culturas suramericanas: Sá describe "génesis múltiple", "transformaciones en curso" y "la naturaleza problemática de los que desean ser 'héroes", 35 y Brotherston escribe sobre "los mitos heroicos convalidados", "que mientras se basan en la lógica patrolineal-umbilical introduce un motivo aparentemente contradictorio: la concepción milagrosa". "La misión de los chiquitos estaba llena de gente con tradiciones míticas de cambios cíclicos transformacionales y partenogénesis transgresiva. El intento de presentar una historia cristiana del alumbramiento virginal y un milagroso héroe subversivo como una historia nueva, en contraste a la vida "violenta" y "supersticiosa" de antes, tuvo que dejar perplejos a los habitantes. En su estudio del posmisional "Sermón de 40 horas", Riester registra que los chiquitanos del siglo XX (el uso de la palabra "chiquitano" data de la segunda mitad del siglo $\mathrm{XX}^{37}$ ) "aceptaron lo 'folklórico' de la iglesia católica, sus formas en algunos aspectos, pero no los contenidos". ${ }^{38}$ Se me ocurre que entre los chiquitos del siglo XVIII, a quienes se les dio solo una versión sencilla de cristianismo, y que no fueron afectados por la idea que ésta fuera transgresiva, surgió el entendimiento de que lo que importaba era lo físico del ritual, no la doctrina que lo sustentaba.

En la opinión jesuita un defecto de los chiquitos antes de ser cristianos distinto de otra gente de la región- fue la falta aparente de ceremonias religiosas. No

\footnotetext{
${ }^{32}$ Ibid.: 162.

${ }^{33}$ Matienzo, 2011: 188.

${ }^{34}$ Durkheim y Mauss, 1963: XXXVIII " [. . . the principles of the extant social classification are inoperative or are flouted".

${ }^{35}$ Sá, 2004: XVII "multiple genesis [. . .] on-going transformations [. . .] and the problematic nature of any who would be 'heroes"'.

${ }^{36}$ Brotherston, 1979: 217 "validating hero myths [. . .] that, while relying fully on the patrolinearumbilical logic, [. . . ] introduce into it an apparently contradictory motif: miraculous conception".

${ }^{34}$ Riester, 1976: 122 "La autodenominación de estos indígenas hoy en día es la de Chiquitano".

${ }^{38}$ Riester y Fuss, 1986: 71.
} 
obstante, el P. Burgés escribió que, antes de ser reducidos, los chiquitos daban la bienvenida al amanecer al tocar flautas hasta que secara el rocío. ${ }^{39}$ Es posible que esa costumbre fuera de hecho una forma de comunicación ritual con los "jichis" (espíritus) de la tierra y el agua. El uso de flautas distintas para marcar las estaciones entre los chiquitanos de hoy ${ }^{40}$ [Fischerman y Quiroaga, Vaca Céspedes] parece dar respaldo a esta conjetura. En todo caso, los misioneros adaptaron la práctica, como escribió el P. Knogler: "Todos los días bien temprano tocamos las campanas para reunir al pueblo". "El ritual de diálogo con los dioses que tenían los manasicas y sus cocreyentes antes de ser reducidos fue reemplazado por el ritual litúrgico y sacramental de la Iglesia Católica. Ambos sistemas de creencia incorporaban a la "voz" de una suprema autoridad y a los suplicantes. Sin embargo, no hay razón para creer que el cinismo manasica en relación a las declaraciones de sus dioses desapareciera una vez que cambiaron los rituales y las figuras autoritarias. Ya había escrito el P. Caballero "y así algunos mosos intrépidos, quando oyen a los Demonios semejantes proposiciones, suelen desir [sic] mienten los Dioses, como suelen". ${ }^{42}$ Fischerman observa que los sacramentos de la Iglesia no les importaban a los chiquitos. ${ }^{43}$ En la época republicana que describe, los chiquitos "fosilizaron" el ethos y la práctica jesuita para que les mostraran su estatus de "civilisados" a los usurpadores blancos de las estancias ex-misionales. Si las cosas hubieran sido así en aquel entonces, además en los tiempos de los chiquitanos del siglo XX investigados por Riester, ¿seguramente habría pasado lo mismo en la época misional?

Los ritos cristianos eucarísticos se basan en la sangre y el sacrificio violento de la tradición semita. ${ }^{44}$ No hay ningún registro histórico del sacrificio de animales o seres humanos a los dioses en el Oriente, sólo se registran ofrendas. ${ }^{45}$ Empero la eucaristía católica consistía en comer regularmente el cuerpo de una de las dos figuras claves del catolicismo misional (la Virgen y su Hijo). Para que esta costumbre, la que Kraniauskas describe como "el canibalismo simbólico de la liturgia católica", ${ }^{46}$ fuera aceptada por los miembros indígenas de la misión -denigrados en las Anuas con infundadas acusaciones de ser "Caribes" hay que suponer que nunca se les explicó o, tal vez, que no había el deseo de cuestionarla. En el mundo indígena ofrendas a las deidades consistían en un quid pro quo -si se daban alimentos a las deidades, éstas a cambio predecían donde cazar, o prometían cosechas buenas. El sacrificio expiatorio de la cruz no tenía antecedentes en el Oriente.

\footnotetext{
${ }^{39}$ Burgés, 2008: 93.

${ }^{40}$ En la Chiquitania de hoy, el "topurr" o "topüx" es una flauta transversa de $110 \mathrm{~cm}$ de largo con la embocadura en el final opuesto ello de dos orificios para los dedos. Se la toca de julio a octubre durante la siembra y la chaqueada, y para avisar de eventos próximos; el "naturrürr" o "natiraïx", un pífano de tono alto se toca desde el principio de enero hasta el Carnaval (Fischerman y Quiroaga, 1996: 5). Se toca el "secu-secu" o "yoresox", zampoña de llamar y respuestas, en la Pascua (Vaca Céspedes, 2010: 71,75).

${ }^{41}$ Knogler, 1979: 173.

${ }^{42}$ Caballero, 1933: 25.

${ }^{43}$ Fischerman, 1995: 390.

${ }^{44}$ Fitzpatrick, 1993: 62. Hubert y Mauss, 1946: 125.

${ }^{45} \mathrm{Cf}$ Karsten, 1968: 379 "A salient feature in the religion of the primitive Indians east of the Andes is the insignificant part sacrifices and offerings play in it".

${ }^{46}$ Kraniauskas, 1998: 153 "the symbolic cannibalism of Catholic liturgy".
} 
La hostia no es de carne, sino es un barquillo de harina. Muchos miembros de la misión de los chiquitos tenían una tradición cultural en la que un chamán succionaba un espíritu malévolo del cuerpo de un enfermo antes de escupirlo en la forma de un objeto pequeño mojado en sangre o líquido negro. El proceso entero estaba acompañado por rituales para asegurar la recuperación del paciente. ${ }^{47}$ Riester señala la creencia de los chiquitanos del siglo XX (supuestamente heredada de sus antepasados) que un chamán podía causar daño a una víctima por medio de un pelo o pedacito de uña cortada. ${ }^{48}$ Culturalmente se aceptaba la transformación sobrenatural de lo intangible (un espíritu malévolo) a lo tangible (tal vez una piedrita o un palito) mientras que se creía que el alma humana estaba en cosas tan efímeras como cada pelo o pedacito de uña. En este contexto se puede ver cómo el concepto de transubstanciación sin duda visto por los misioneros como algo fuera de la comprensión indígena en ese tiempo- pudiera haber sido considerado por ellos mismos como meramente una manifestación nueva de la antigua creencia. Según Taussig: "la fluidez, habilidad y perfección física con que el chamán hace sus trucos de magia" contribuían a una presentación valorada tanto por su técnica como por su eficacia. ${ }^{49}$ Eso nos da a entender que el ritual litúrgico de la eucaristía pudiera haber formado un elemento intrínseco y necesario en la transformación mágica en la percepción de los indígenas.

Durante el período de la restauración de los templos de la misión que empezó en el año 1972, el arquitecto jesuita Hans Roth que inició la restauración de los templos en los años 1970 halló una colección de palitos en Santa Ana que tenían inscritos las palabras "Está confesado" en el idioma chiquito. Un penitente no podía comulgar hasta que recibiera un palito después de confesarse. ${ }^{50}$ ¿Sería posible que las personas que recibían estos palitos los consideraran una ofrenda? El canje de una ofrenda (un palito poderoso en virtud de la persona que la daba) por la promesa de lo bueno por venir, presente en el acto de comulgar, tendría que estar de acuerdo con las tradiciones de antaño.

Debido a que existía poco entendimiento de la doctrina católica entre los neófitos, hay que suponer que el ritual físico -es decir la "coreografía" de la práctica litúrgica- jugaba una parte imprescindible. Brotherston describe la manera en la que el ritual establece su espacio propio: "donde se da orden y significado a lo aleatorio y lo circunstancial por medio de adornos y estructuras, y por las posiciones, ropaje y gestos ordenados de los actores". 51

\footnotetext{
${ }^{47}$ Caballero, 1933: 29 "Viene el enfermo al hechisero, o él ba a él: pregúntale de su enfermedad ... dísele que la causa son siertas almas de animales, que tiene en el cuerpo [. . .] Chúpales la parte dolorida, y al punto les pone el Demonio en la boca sangre, que de ordinario ven negra, que muestra al doliente." Cuando el mapono lo hizo (en contra de un chaman de menos estatura) "arroja de su boca tanta cantidad de sangre, que parese increíble cupiese en la boca, y lo es más salga del enfermo, sin agugerear la piel; a beses saca vna bíbora del largor de vn dedo, que a pocos instantes crese, y se hase de a bara, y le da de comer, y beber".

${ }^{48}$ Riester, 1976: 167.

${ }^{49}$ Taussig, 2006: 140 "[. . .] the fluidity, skill and physical perfection with which the shaman performs his tricks".

${ }^{50}$ Conversación con Pedro Querejazu, 2.2.11.

${ }^{51}$ Brotherston, 1979: 83-84 "[ . . .] where the random and the circumstantial are given order and significance, in the forms of ceremonial objects and structures, and of actors with given positions, gestures and dress".
} 
El P. Knogler describió el orden en el que la feligresía fue agrupada en la iglesia, un orden mantenido por ellos mismos:

"A partir del enrejado del comulgatorio, forman el primer grupo los muchachos y jóvenes que están arrodillados delante del altar, vigilados por sus capitanes o celadores quienes son muy celosos en el ejercicio de su cargo y castigan una falta cometida durante el culto divino en seguida que termina éste. Luego siguen los hombres cuyo grupo llega hasta el centro de la iglesia. Detrás de ellos están postradas las muchachas con sus inspectoras, y al final vienen las mujeres cuyas jefas observan desde la puerta a su grupo y a la reunión entera". 52

Se considera que el diseño de las losas de la iglesia de San Javier, de configuraciones distribuidas en las distintas áreas, debe haber sido un indicativo de los lugares asignados a los grupos de edades diferentes o géneros diferentes. ${ }^{53}$ Los comulgantes (comulgaban de una a cuatro veces al año) eran organizados muy estrictamente:

"Todos los comulgantes son llevados en orden hacia el altar por los celadores que han sido designados para conducir los grupos sin confusión y trastornos. Cada uno camina con las manos elevadas y los ojos bajos, vestido como siempre de manera pobre pero decente, de color blanco, descalzo, sin los adornos, como plumas o pinturas, que usan comúnmente". ${ }^{54}$

Brotherston continua, expresando que:

"Para adorar o exorcizar, para animar o negar, estos participantes se comportan como danzantes en un escenario o como equipos en un juego de cuyas reglas y los límites son reconocidos convencionalmente. ",55

La aceptación a una "coreografía" mandada obviamente por los jesuitas en la misión, nos da a entender que, tal vez, una percepción indígena de la importancia de ubicarse ritualmente en un espacio sagrado se hubiera remontado al período premisional. En ese tiempo el respeto indígena a lo sobrenatural se manifestó por medio del cumplimiento de un código de comportamiento basado en una creencia de la necesidad de defenderse contra espíritus malos, o apaciguarlos, algo que disuadía todo deseo de hacer cambios. Habría parecido una locura meterse con fórmulas clásicas de éxito probado. Sostengo que la gente pensaba que los procedimientos rituales dentro de la iglesia de una misión tenían una eficacia genérica debido a su regularidad y su previsibilidad. Lo importante era la naturaleza holística del ritual, no los elementos individuales. Tal vez este holismo explique el hecho de que nunca ha sido sacado a la luz una partitura de la misión de chiquitos de irrefutable autoría indígena; ${ }^{56}$ seguramente la música de la iglesia, compuesta allá o llevada allí por los misioneros, habría

\footnotetext{
${ }^{52}$ Knogler, 1979: 174.

${ }^{53}$ Roth, 1995: 508; Suárez Salas, 1992: 259.

${ }^{54}$ Knogler, 1979: 176.

${ }^{55}$ Brotherston, 1979: 84 "To worship or exorcise, to encourage or negate, these participants behave like dancers on a stage or teams in a game whose rules and boundaries are conventionally recognised."

${ }^{56}$ Waisman trata este tema, atribuyendo la ausencia al deseo de los músicos indígenas de reproducir la música misional exactamente, debido a su percepción de su propia posición societal inferior y el "poder” de una composición no estropeada por ellos mismos (Waisman, 2013: 9).
} 
sido reconocida como una parte intrínseca de la totalidad de la misa y, por consiguiente, del punto de vista de un músico indígena, al hacer interferencia arriesgara poner en peligro la balanza de poder, tanto natural como sobrenatural y, en consecuencia, la sobrevivencia. Claramente la gente indígena había aceptado el yugo de control católico para tener más posibilidades de sobrevivir.

Era beneficioso para los chiquitos aceptar las reglas del "juego" (para usar la palabra de Brotherston). Ellos fueron la primera etnia en ser evangelizada y, por eso, visto por los jesuitas como dignos de confianza. La estructura gobernante de una misión siguió la Recopilación de las Leyes de los Reinos de Indias de 1680, salvo que los indígenas, no los españoles, ocuparían las posiciones de autoridad. Aunque los funcionarios no tuvieran ningún poder en realidad, al ser subyugados a la jurisdicción sacerdotal, ejercían mucha influencia, como escribió el P. Knogler:

"Pues cuando los mayores y los que gozan de mucho prestigio se portan bien, arrastran también a su gente, en parte por su ejemplo, en parte por sus órdenes expresas y reiteradas exhortaciones". 57

Con el oficio venían uniformes y regalías impresionantes para las ceremonias litúrgicas. En mi opinión esas decoraciones, junto a los desfiles y la música, fueron "la tecnología de encanto", como Gell le da el nombre a la destreza técnica requerida para cautivar a un súbdito. La técnica permitió a la gente sentir lo que el mismo Gell, en un juego de palabras, describe como "el encanto de la tecnología", es decir "el poder que tienen los procesos técnicos para hechizarnos a nosotros de tal manera que veamos el mundo real en una forma encantada". 58 La "presentación" de una misa en los templos de los chiquitos hechizó a los fieles, aprovechándose de la tecnología de encanto para crear un estado de ánimo y un espacio conceptual donde pudiera suceder, como Taussig escribe de los procedimientos chamánicos, "la mezcla de fe y escepticismo que la magia requiere". 59

\section{2. "Modus illium procendi"}

Invento esta frase para indicar un cambio de énfasis en lo que sigue desde los protagonistas gobernantes hasta los protagonistas gobernados. Esta sección describe dos elementos del catolicismo misional en los que las costumbres y creencias indígenas (registradas tanto por los cronistas del siglo XVIII como por los autores de los siglos XX/XXI) resuenan de tal manera llamativa que la aportación jesuita pasa a segundo plano.

\subsection{Representaciones figurativas bidimensionales y tridimensionales}

En vista de que habría habido un entendimiento dual de la doctrina de transubstanciación, es interesante prestar atención a lo que considero haber sido una ambigüedad semejante a la que la gente tenía al contemplar las imágenes visuales figura-

\footnotetext{
${ }^{57}$ Knogler, 1979: 178.

${ }^{58}$ Gell, 1992: 43-44 "the technology of enchantment", "an art object", "the enchantment of technology", "the power that technical processes have of casting a spell over us so that we see the real world in an enchanted form".

${ }^{59}$ Taussig, 2006: 50 "the mix of faith and scepticism necessary to magic".
} 
tivas de la Iglesia. Es difícil creer que los feligreses se identificaran con las figuras europeas sufridas y extáticas -pálidas, de rostros delgados y frentes altas- que lucieron de estampas de Cristo, la Virgen y los santos. Por el contrario, la evidencia sugiere que la relación con imágenes de papel no trató del tema de la estampa, sino del papel mismo. Cuando "apariciones horrorosas, ruidos y espantos" molestaron la misión de San Rafael entre los años 1713 y 1719, los sacerdotes pusieron fin a estas visitas al colocar estampas de San Ignacio en las entradas de sus propios cuartos:

"Aconsejaron esto mismo los padres a los indios, dándoles las estampas de San Ignacio nuestro padre que tuvieron y, no alcanzando para todos, que las pedian con instancias, suplieron su falta con el nombre del santo escrito en un papel". ${ }^{60}$

Cualquiera fuera la forma tomaron las marcas, el remedio fue eficaz. No había más fastidio, sino una devoción renovada al santo. ${ }^{61}$

Estampas de la Virgen eran portadas como estandartes por los miembros de una "caza espiritual" cuando el grupo se acercaba a un asentamiento indígena. ${ }^{62}$ Diez Gálvez cita un relato del P. Juan de Montenegro sobre la muerte del P. Agustín de Castañares a manos de los mataguayos, en el cual mencionó el uso como manto por uno de los mataguayos de "una imagen de la Virgen del Pilar, pintado en lienzo", saqueada del fallecido, "según su usanza"”, 63 El P. Knogler observó la costumbre regional de vestirse con cueros de animales; ${ }^{64}$ y es posible que los mataguayos fuera la etnia a la que se refiriera. Si los mataguayos creían que el poder y ferocidad de un animal cazado serían trasferidos a quien llevara la piel alrededor de los hombros (como describe Karsten de los tobas del Chaco ${ }^{65}$ ), llevar un trofeo asociado con un oponente poderoso parecería algo acertado. Ya había en la espiritualidad indígena el concepto de la "Reina de Cielo" (para usar la construcción cristiana) o la luna como madre. Para los manasicas y sus co-creyentes una diosa, Quipozi, era la madre de un hijo poderoso, una de las tres deidades varoniles del panteón manasica. Por casualidad la idea de la Virgen cayó en tierra fértil, pero el papel o el lienzo en el que estaba su retrato fue donde residía el poder. ${ }^{66}$

Se puede imaginar que la representación figurativa escultural tendría que jugar un papel más proactivo por razón de su tamaño y tridimensionalidad. Diez Gálvez registra la posibilidad de que hubiera unos talleres misionales dedicados a la producción de imágenes esculpidas, debido al hecho de que ciertos métodos y rastros estilís-

\footnotetext{
${ }^{60}$ Matienzo, 2011: 131 (en una adición a la Anua de 1714-1720).

${ }^{61}$ Se notan en los Inventarios del año 1767 cuatro cuadernos de estampas de varios santos en los cuartos de Gaspar Troncoso y Martin Schmid en San Ignacio (Brabo, 1872: 500). En vista del trabajo de Schmid como diseñador/arquitecto, tal vez los marcos de estas páginas inspiraran los portales decorativos, si no se los requieran para el uso práctico de 50 años antes.

${ }^{62}$ Diez Gálvez, 2006: 352.

${ }^{63}$ Ibid.: 355. Combès, 2009: 183 da el relato completo.

${ }^{64}$ Knogler, 1979: 140. "He visto una tribu cuyos hombres llevan adherido al cuello un cuero de tigre resecado que mueven de un lado al otro según el viento que corre y que les sirve de colchón."

${ }^{65}$ Karsten, 1968: 73.

${ }^{66}$ Caballero nos da dos ejemplos de la recuperación de indígenas no-reducidos a quienes impuso imágenes de la Virgen (Caballero, 1708: 62-63) o de la Virgen y de San Miguel (Caballero, 1708: 71).
}

58 Kate Ford. “Hijos de los jesuitas” o ¿Hijos de su propio pasado?... 47-79. 
ticos de la escultura de la misión son identificables por todas partes. ${ }^{67}$ Las estatuas misionales eran talladas de madera o maguey, con carne visible enyesada, y ropa de lienzo mojado de yeso para hacer pliegues ondulados, o cosido de tela importada del color apropriada a cualquier fiesta de la Iglesia. Los ojos de vidrio fueron puestos en la cabeza por afuera o por adentro. Las estatuas de la Virgen tenían adornos de plata. ${ }^{68}$ Después de volver de su viaje a la región de los manasicas (1706), el P. Caballero preguntó a uno de sus intérpretes (un joven de San Javier que estaba familiarizado con la imaginería católica) cómo había descrito las imágenes religiosas a su familia. El joven le contestó ingenuamente, al mostrar los defectos de una conversión superficial: "'direles [sic] ¿qué os parese [sic] que respetan los cristianos? Vnos liensos [sic], vnas figuras de piedras, o palos, que no hablan "," 69

Los artesanos indígenas tallaron, pintaron y enyesaron las figuras en talleres misionales. ${ }^{70}$ Se podría suponer que el consuelo ofrecido por las diversas estatuas de San Miguel o San Rafael, o de ángeles con trompetas, o de las Vírgenes Inmaculadas -más o menos de tamaño natural, de rostro raso y adolescente con las mejillas rosadas- se asoció con la autoridad del personal europeo de una misión y, tal vez, con la semejanza física de las estatuas a estas personas. Los indígenas no fueron las criaturas sencillas e infantiles descritas por los cronistas; podían razonar. La estatuaria de la Iglesia, al igual que el ritual, funcionó como recuerdo de su posición en la balanza de lo natural/sobrenatural mientras que epitomó la seguridad de la vida misional.

Puesto que la representación figurativa fue algo nuevo para los chiquitos (en mi opinión la declaración del P. Caballero en su "Diario" que destruyó "ciertos idolillos y figuras "71 indígenas fue propaganda romántica dirigida a sus lectores europeos), es interesante tomar nota del ejemplo del retrato escultural evidente en dos iglesias, en el que parece que los artesanos dejaron los modelos europeos. Los Inventarios de 1767 registraron el retablo mayor y los altares de la Virgen y del Calvario de la iglesia de San Miguel como "bien labrado", ${ }^{2}$ mientras que el púlpito no mereció una mención. Los altares fueron tallados por el misionero Martín Schmid. Hans Roth escribe del trabajo del P. Schmid en otra iglesia misional, la de San Ignacio: "se ven en serie los contrastes iconográficos entre maestro y discípulos". ${ }^{73}$ El sostén del púlpito de San Miguel es rodeado por cariátides curiosas, popularmente descritas como "sirenas". Hay figuras semejantes alrededor del sostén del púlpito de chapa de mica de San Rafael que parecen choclos de cabeza humana (Fig. 1) ${ }^{74}$.

Distintas de las sirenas del arte popular del siglo XVIII, no tienen un torso femenino y la cola de pez, sino sólo una cabeza encima de algo. ${ }^{75}$ Tal vez representan el cuerpo estilizado de un ave del tipo arpía que pudiera haber sido copiado de un grotesco de

\footnotetext{
${ }^{67}$ Diez Gálvez, 2006: 326-327.

${ }^{68}$ Ibid.: 327-328.

${ }^{69}$ Caballero, 1933: 23.

${ }^{70}$ Diez Gálvez, 2006: 325-328, 363.

${ }^{71}$ Caballero, 2011: 80-81.

72 Brabo, 1872: 507.

${ }^{73}$ Roth, 1989: 38.

${ }^{74}$ Observación de Andrea Nicklisch, 10.8.12

${ }^{75}$ Querejazu, 2000: 121.
} 
alguna estampa del renacimiento en una biblioteca sacerdotal. Una necrología del P. Juan de Benavente, el compañero del P. Caballero en la expedición a los manasicas, fue incluida en la Anua de 1750-1756; era una expedición "muy ardua" debido en parte a las fieras que rondaban la región que los misioneros atravesaron:
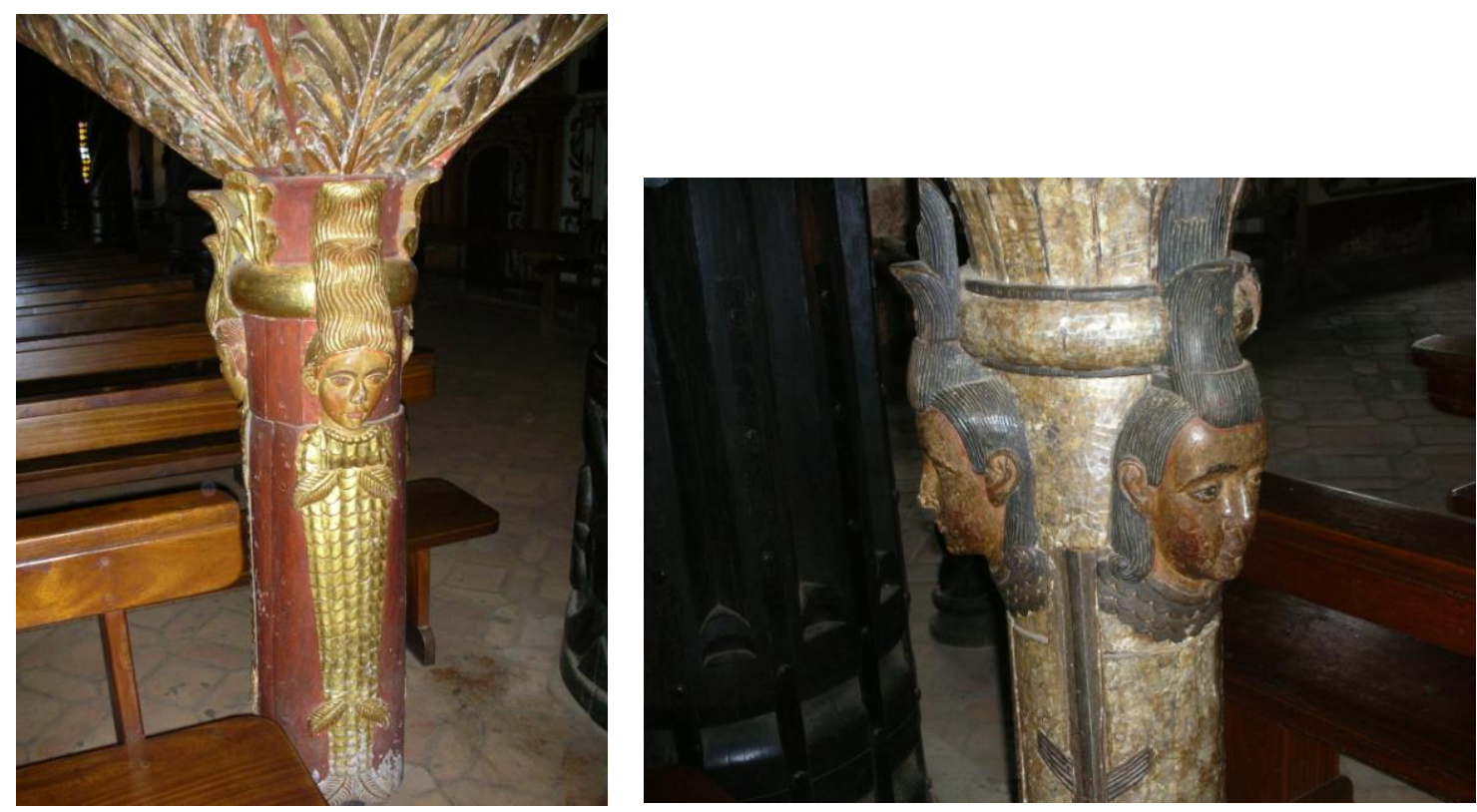

Fig.1 Figuras de naturaleza ambigua moldeadas y doradas alrededor del sostén del púlpito de San Miguel (a la izquierda) y pintadas y cubiertas de mica en San Rafael (a la derecha) (fotos: la autora, 2010 y 2011).

"existe allí una clase de aves, semejante a las arpías, las cuales salen de sus cuevas subterráneas para asaltar a los transeúntes, peleando con tanta porfía que no cesan hasta lograr matar al viajero, o morir en la demanda. Tiene la cabeza a semejanza de un tigre, y un cuerpo como un perro". ${ }^{76}$

El P. Caballero hace una referencia a una criatura semejante a principios del "Diario":

"pero a ellos [el pueblo napasina (mapasina) o papasinaca] casi han acabado o ahuyentado un género de animales del cuerpo de un pequeño pájaro, más de tan rara fuerza y fiereza que, en viendo gente, vuelan y degüellan a una persona. Venen debajo de tierra, y se llaman peresuica". ${ }^{77}$

Si las cariátides de los púlpitos fueron hechas para representar aves de rapiña dispuestas alrededor del sostén, tal vez su trabajo asignado por los talladores era dar protección al sacerdote, o a sus palabras. Pero las cabezas de las figuras del púlpito de San Miguel no parecen tigres; más bien sus caras tienen las narices anchas con ventanas acampanadas que formaban parte del diseño de un tazón pequeño encontrado en

\footnotetext{
${ }^{76}$ Matienzo et al, 2011: 343.

${ }^{77}$ Caballero, 2011: 47. Szabó, 2008: 136 anota Polyborus plancus, un ave de rapiña de las tierras bajas, del nombre "carcancho", al cual las Tobas y los Isozeño-Chiriguanos atribuidieron poderes sobrenaturales; Cunninghame Graham, 1901: 255 y nota de pie, se refiere a "caranchos", "Polyhorus tharus", una corrupción de su nombre nativo "traré", como un ave del tipo buitre que comió carroña.
}

60 Kate Ford. "Hijos de los jesuitas” o ¿Hijos de su propio pasado?... 47-79. 
una urna funeraria desenterrada por Riester en piso firme (Fig. 2). ${ }^{78}$ Igualmente sus pelos están esculpidos en una cofia alta del estilo de la gente indígena de la región cercana de San Miguel antes de la misión, para lo cual se usaba pasta hecha de la fruta del urucú. ${ }^{79}$ Quizás podrían representar Hichi-tuúrsch, el jichi de las aguas en la cosmovisión chiquita, metamorfoseando en forma humana; o tal vez simbolizan Toírsch, el jichi del cultivo, apaciguado por un choclo quemado. ${ }^{80}$ No hay razón para creer que sean figuras femeninas. La semejanza de sus rostros a los de las vasijas antiguas que tampoco tenían cuerpos humanos se debe al hecho de que los talladores estuvieron moldeando figuras del estilo europeo de manera que tuviera significado para ellos.

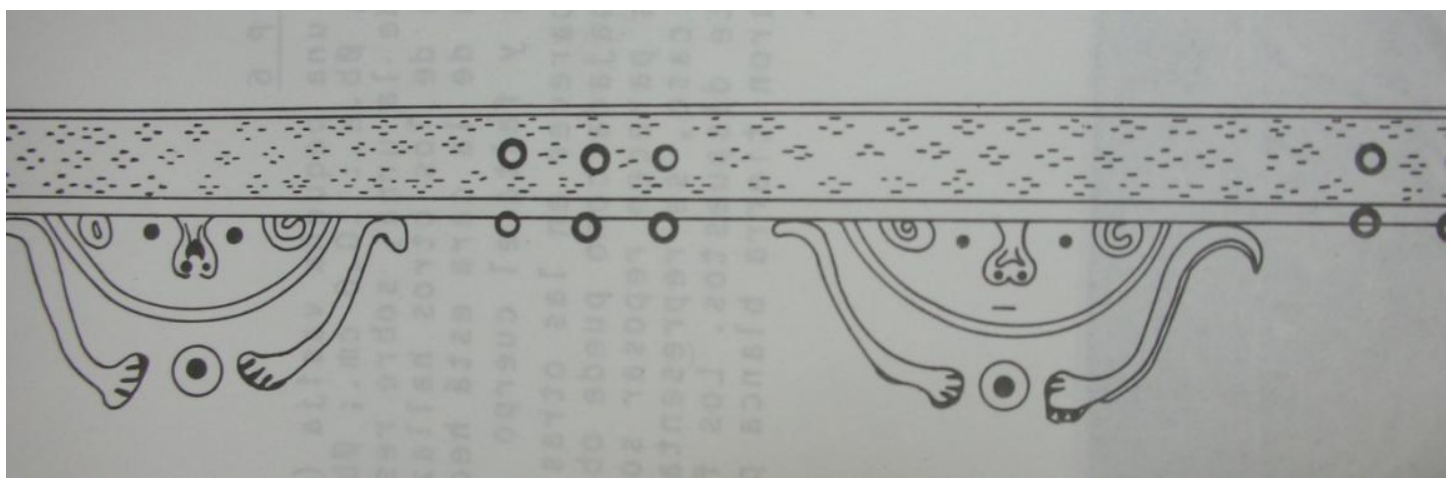

Fig. 2 Bosquejo esquemático de una banda grabada en la circunferencia de una vasija desenterrada en Piso Firme (foto: Riester, 1981: 44).

"Los artistas indígenas comienzan a expresar su alma en lenguaje barroco", concluyó Roth, de San Ignacio. ${ }^{81}$ Los dos soldados responsables de hacer los Inventarios del año 1767 no valoraron algunos cuadros por haber sido pintados por artesanos indígenas, como Diez Gálvez nos da a entender. ${ }^{82}$ Tampoco los púlpitos de San Miguel y San Rafael merecieron un registro, de manera que se puede asumir que los talladores fueron indígenas. ¿Es mejor decir sobre las "sirenas" que el barroco comenzó a ser expresado en lenguaje indígena?

\subsection{Devoción al viático}

El registro del entusiasmo con que los chiquitos solían acompañar el viático fundamenta mi hipótesis de la importancia de ritual per se en la misión y el entendimiento dual de la doctrina de transubstanciación y de la imagenería misional. Creo que este entusiasmo por el sacramento se debió más a la creencia chiquitana registrada por Riester que tomar posesión de un recorte de uña o un pelo le daría a un

\footnotetext{
${ }^{78}$ Riester, 1981: 43.

79 Freyer, 2000: 69, citando la explicación de Riester de los ingredientes de la pasta en su edición del Relato de Knogler publicado en el año 1970. Knogler empleó la palabra "tierra” (Knogler, 1979: 140 "Otros se ungen con tierra rodena, embardonándose especialmente la cabeza, de modo que parecen llevar puesto un casco de punta." Bixa arellana es el nombre botánico del urucú.

${ }^{80}$ Birk, 2000: 202.

${ }^{81}$ Roth, 1989: 38.

${ }^{82}$ Diez Gálvez, 2006: 362.
} 
"oboírsch" (chamán malo) el poder de hechizar a alguien. ${ }^{83}$ El deseo de asistir al viaje de las sustancias sobrenaturales del viático era provocado por el deseo de ganar poder por proximidad.

En la Anua del período 1735-1742 se escribió:

"Especial alabanza merece la piedad de los neófitos de San José, con la cual suelen acompañar al santísimo sacramento, cada vez cuando hay que llevarlo de viático a los enfermos. Ordinariamente lleva la gran comitiva más de 200 velas encendidas a lo largo del camino, arrojando flores y hojas [. . .] Cierta noche, exigió la gravedad del estado de un indio que se le llevase el viático. La hora era ya avanzada y no se llamó a nadie, sin embargo casi todos los narlo", 84 habitantes del pueblo se levantaron de la cama y acudieron para acompa-

Un pedido del sacramento puso a un lado otras prioridades, como se plantea el Estado del Pueblo de San José del año 1742:

"Y de la misma suerte hacen, cuando sin haber tenido noticia, ven desde sus casas salir de la iglesia al padre con el Señor para el enfermo, que al punto dejan cualquier cosa que están haciendo y corren a acompañar al Señor a la casa del enfermo, y después al sacerdote hasta la iglesia. Y hacen con tanto esmero esta devoción que si les da lugar el tiempo, como sucede de ordinario, luego los capitanes mandan a las mujeres que viven en las calles por donde ha de pasar el Señor, que las barran y limpien, y aderezan la puerta de la casa del enfermo, con ramas y hojas de árboles verdes y olorosas". ${ }^{85}$

La ceremonia concomitante a la procesión del sacramento muestra el respeto que la gente tenía para el viático. También había un temor de morir al no recibirlo.

"[L]os moribundos esperaban [el sacramento] con el más grande deseo. Y si después del viático se prolongaba todavía su vida, no dejaban de suplicar que se les permitiese, a mayor alegría de su corazón, recibir la segunda vez. este divino manjar. Las madres eran tan solícitas de la salvación de sus hijos, que se fijaban mucho en descubrir si eran capaces ya de malicia para que, en este caso, no muriesen sin la extremaunción". 86

La convicción de que el viático otorgara poderes sobrehumanos a alguien que lo recibía (y, se hubiera esperado, a los que lo acompañaban) habría sido reforzada con la recuperación de algunas personas. Tan entusiastas eran los miembros de la misión de recibir este remedio mágico que en un documento complementario a la Anua de 1742-1749 se expresó que los misioneros tenían que verificar la validez del pedido antes de comenzar su visita. ${ }^{87}$

\footnotetext{
${ }^{83}$ Riester, 1976: 167.

${ }^{84}$ Matienzo, 2011: 216.

${ }^{85}$ Ibid.: 286.

${ }^{86}$ Ibid.: 236 (Anua de 1735-1742).

${ }^{87}$ Ibid.: 292-293 (Documentos complementarios a la Anua [1743]-1750: Años 1742-1749).
}

62 Kate Ford. "Hijos de los jesuitas” o ¿Hijos de su propio pasado?... 47-79. 


\section{Templos protegidos}

Este artículo concluye que los templos de la misión fueron adornados con decoraciones que los jesuitas consideraban eran para disfrazar el método y los materiales humildes de construcción, mientras que los chiquitos pensaban que éstas ofrecían protección al edificio contra la ira espiritual.

\subsection{El carácter corpóreo del templo}

Los chiquitos del siglo XVIII consideraban que cada templo era una entidad que debía ser protegida; esta creencia no solo se trató de la superficie, sino también del barro mismo con el que se formaron los adobes. Taussig cita el cuerpo humano como medio universal para

"la exposición de lo interior y lo exterior, de penetración y recuperación, y, por consiguiente, de destripamiento y desenmascaramiento de fondos escondidos en presentaciones espectaculares de la ocultación y la revelación" ${ }^{8}$

Ya eran englobados en las prácticas rituales del Oriente "lo interior y lo exterior"; mucha gente indígena tenía una tradición cultural de ver a un chamán que succionó un espíritu malévolo de un cuerpo afligido antes de escupirlo en forma tangible. Se usaba saliva para mojar pigmentos con los que se pintaba la piel, ${ }^{89}$ y el vómito de un mapono manasica para ungir la espalda de un candidato al sacerdocio. ${ }^{90}$ Según los restauradores de San Javier en los años 1970, los rasgos de los pigmentos originales de la tierra que se quedaron en las paredes de la iglesia fueron "rojo minio y negro mal bistre", "rosado y gris", "rosácea-ocre" y "blanco-amarillo", 91 los colores carnosos. Cuando sale el sol después de una llovizna en la Chiquitania en la temporada de las lluvias, el olor de tierra caliente y mojada tiene una presencia casi física. Las paredes de los templos misionales estaban fijadas en la tierra, sin cimientos, ${ }^{92} \mathrm{y}$ eran hechas de esa misma tierra, y fueron pintadas con pigmentos también de la tierra (Fig. 3). ${ }^{93} \mathrm{El}$ acto de sacar barro del suelo para hacer adobes usados en la construcción del edificio icónico de una iglesia representó "lo interior y lo exterior", igual que el uso de fluidos del cuerpo para reforzar el status quo natural/sobrenatural. Turner propone que el cuerpo humano es el sitio de "un discurso carnoso, dentro del cual pueden ocurrir la interpretación como también el sostenimiento de las relacio-

\footnotetext{
${ }^{88}$ Taussig, 2006: 168. "the staging of insideness/outsideness, of penetration and retrieval, and hence of evisceration and exposure of hidden depth in often spectacular performances of concealment and revelation".

${ }^{89}$ Bórmida y Califano, 2003: 91-93.

${ }^{90}$ Caballero, 1933: 29-30 “[E]mbriágase primero el Mago ansiano, y tomando una Tutuma [. . .] comiensa a Vomitar una maretia negra y hedionda, como goma [. . .] Este es el Olio con que es unjido el nuebo sacerdote, a quien unge el sacerdote viejo los brasos, y espaldas [ . . .]"

${ }^{91}$ Roth, 1995: 467.

92 Ibid., 1989: 35.

${ }^{93}$ El mapa de Kaifler (Kaifler, 1993: 59-61) indica cuatro sitios entre San Ignacio y San José, y otro a Chochis en ruta a Santiago en el este, donde se hallan los óxidos de hierro para hacer los colores rojo oscuro, rojo claro, negro y amarillo ocre. De estos sitios vinieron los pigmentos de las pintas usadas para la restauración de los templos en los años 1970.
}

63 Kate Ford. “Hijos de los jesuitas” o ¿Hijos de su propio pasado?... 47-79. 
nes societales del poder". ${ }^{94}$ Una iglesia de la misión de los chiquitos -el cuerpo místico de Cristo para los jesuitas, el cuerpo físico relacionado intrínsecamente a la tierra, y que necesitó protección del daño sobrenatural, para los chiquitos- era también el sitio de un discurso. Fue un discurso en el que las relaciones de poder cósmico (deidad/deidades todopoderosos versus seres humanos indefensos) y las relaciones de poder societal (la Iglesia católica encarnada por los misioneros versus la gente de creencias vilipendiadas) pudieron ser asimismo interpretadas y sostenidas.

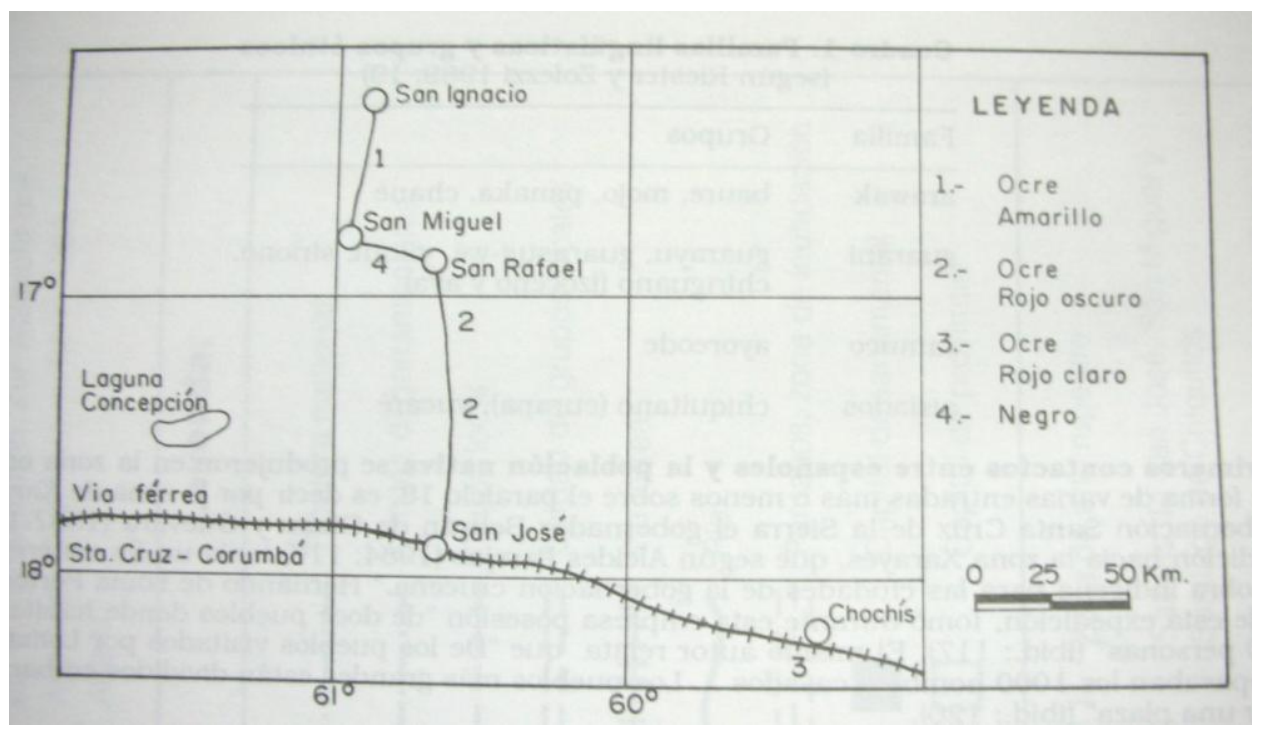

Fig. 3 Mapa de sitios del Oriente de los óxidos de hierro para hacer los colores rojo oscuro, rojo claro, negro y amarillo ocre (mapa: Kaifler, 1993: 61).

Kühne explica que:

"[u]n estilo arquitectónico europeo que pudiera ser replicado en las Américas con tecnología sencilla y materias primas baratas resultó en la construcción de templos con columnas de soporte de madera". 95

En la misión, este estilo imita por casualidad el método de techo sobre palos empleado por los chiquitos antes de la llegada de los jesuitas para construir una casa grande y abierta al aire libre que se usaba para celebraciones, agasajos y la separación de hombres y de muchachos. ${ }^{96}$ De suma importancia fue la materia prima de la iglesia: el barro. Fraser señala que en el Perú de los siglos XVI y XVII: "las iglesias hechas con barro o pasto no eran consideradas iglesias,$; 7$ también escribe que las iglesias de ladrillos de la costa peruana fueron revocadas y pintadas para que se parecieran de piedra. ${ }^{98}$ Solo fue mencionado en las Anuas como músico el arquitecto de cuatro de

\footnotetext{
${ }^{94}$ Turner, 1996: 27 "a fleshly discourse within which the power relations in society can be both interpreted and sustained".

${ }^{95}$ Kühne, 2008: 25 "Bei den Kirchen mit Holzstützen handelt sich also um einen europäischen Bautyp, der in Amerika pragmatisch, mit einfachen technischen Mitteln und billigen Materialien nachgebaut wurde."

${ }^{96}$ Freyer, 2000: 48, 54-55.

${ }^{97}$ Fraser, 1990: 47 "churches of mud and straw [were not considered to be] really churches at all".

${ }^{98}$ Ibid.: 110-111.
}

64 Kate Ford. “Hijos de los jesuitas” o ¿Hijos de su propio pasado?... 47-79. 
las iglesias de la misión, el misionero Martín Schmid. Su maestría musical fue la razón para que se le mandara a la región. El hecho de que las iglesias no pudieran ser construidas de piedra, ni siquiera de ladrillo, mucho menos de mármol -porque tales materiales no estaban disponibles- fue minimizado entonces por el P. Schmid en sus cartas a su familia. Estos relatos hacen un buen cuento del método (trompe l'oil) usado para superar esta falta; más tarde el Relato del P. Knogler, escrito después de la expulsión, reveló que la falta fue realmente considerada una falta. "[H]acemos cuanto esté a nuestro alcance para que la casa de Dios sea vistosa y respetable”, escribió el P. Knogler, ${ }^{99}$ poniendo buena cara a la situación. Fraser establece claramente la jerarquía de materias primas que se consideraba ser adecuadas para construir una iglesia:

"Se ha atribuido a los tipos diferentes de materiales una jerarquía lineal simple de valor, un valor determinado principalmente por la economía [. . .] [M]ateriales más preciosos son mejores que los que son más baratos, más accesibles. Por lo tanto se consideraba apropiado construir un edificio importante de piedra, de preferencia mármol, por lo menos hasta el siglo XX”. ${ }^{100}$

Por consiguiente - a pesar de la lejanía de la misión, lejos de las sedes autoritarias de Asunción y Córdoba- una vez construidos de adobe y luego enjalbegados, empezó un proceso de "disfrazar" los templos. Marcos para puertas y ventanas fueron moldeados y pegados alrededor de las aberturas, o simplemente pintados bidimensionalmente. Frisos foliados y volutas y geométricas del estilo barroco cubrieron las paredes blanqueadas. Un diseño estilizado en zigzag, semejante al bordado florentino -tal vez hecho con la intención de imitar el patrón de mármol- decoró las pilastras moldeadas. Columnas salomónicas bidimensionales articularon paredes a las que escamas minúsculas de mica dieron la apariencia de superficies cubiertas de hojas de oro o de plata (Fig. 4). El P. Schmid describió San Rafael en una carta a su hermano del 28 de septiembre del año 1761:

"las paredes tienen sus columnas con capitales, pedestales y cornisas, hechas de ladrillos crudos, pero de aspecto bonito a causa de su pintura en diversos colores; así hemos pintado toda la iglesia y los altares".

La índole teatral es muy clara. Un barniz de historia y procedencia arquitectónica le dio una respetabilidad cosmética a un techo sostenido por palos.

Aunque la conformidad a las convenciones del siglo XVIII habría sido la motivación de la decoración planimétrica de los templos, seguramente la gente evangelizada de ese entonces no habría visto el adorno de un edificio tan fundamental a su nueva vida como algo meramente decorativo: lo estético como fin por sí mismo no jugaba ningún papel en el pensamiento indígena. ${ }^{102}$ Lo que sí jugó un papel importante era la costumbre pan-oriental de pintar o tatuar el cuerpo para evitar el daño que inflingía lo sobrenatural. Se podría suponer que el uso de los pigmentos de la tierra y

\footnotetext{
${ }^{99}$ Knogler, 1979: 171.

${ }^{100}$ Fraser, 1982: 42 "a simple linear hierarchy of value has been attributed to different types of material, a value that is determined primarily by economics . . . [M]ore precious materials are better than the cheaper, more accesible [ones]. Thus, at least until the $20^{\text {th }}$ century, it was considered only fitting that a prestigious building should be constructed in stone, preferably marble."

${ }^{101}$ Schmid, 1981: 149.

${ }^{102}$ Karsten, 1968: 200. Wake, 2010: 174.
}

65 Kate Ford. "Hijos de los jesuitas” o ¿Hijos de su propio pasado?... 47-79. 
la materia prima misma, también de la tierra, les dio a los artesanos indígenas la percepción de que la iglesia era un "cuerpo" que igualmente necesitaba ser protegido.

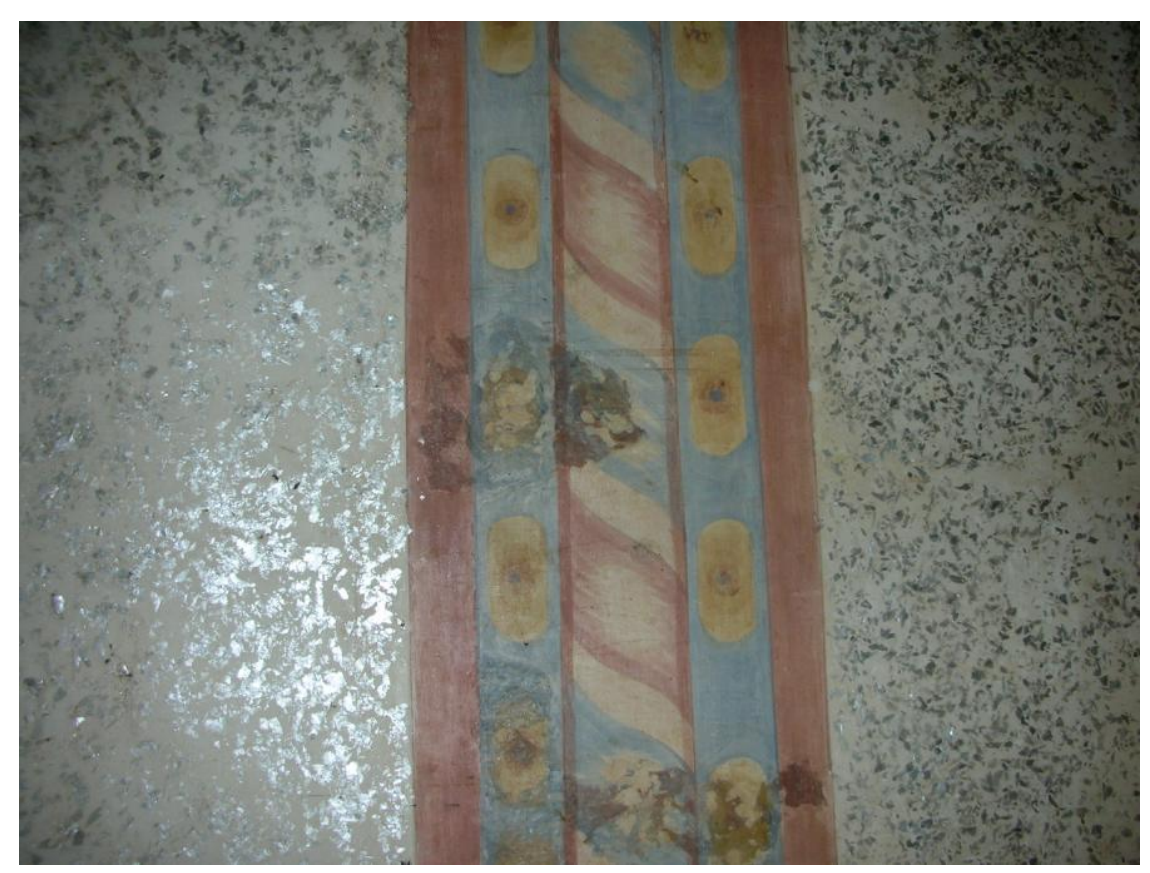

Fig. 4 Columna salomónica ilusionista pintada en una pared cubierta de mica, Santa Ana (foto: la autora, 2010).

\subsection{Los métodos para proteger el cuerpo}

El P. Knogler atribuyó la perforación de los labios, la nariz y los orejas, el alargamiento del lóbulo de la oreja, y la afeitada de las cejas y la cabeza ${ }^{103}$ costumbres común en la gente indígena- a la "naturaleza bárbara" de gente de un "bajo grado de civilización". ${ }^{104}$ Por el contrario, estas prácticas mostraron la naturaleza cautiva de gente convencida de su vulnerabilidad a fuerzas sobrenaturales, y que había desarrollado tácticas con el objeto de que estas fuerzas fueran engañadas o repelidas. En la región entre Amazonía y el Chaco había la difundida creencia que hacer marcas temporales o permanentes en la piel, o perforarla, le daba a una persona fuerza y protección; esto no sólo se creía en la región de la misión, sino al norte, al sur y al este de ella.

Doscientos años antes, Ulrich Schmidel, un mercenario bávaro, había escrito que los xarayos del río Paraguay aguas arriba, se pintaban el cuerpo (de hecho, probablemente se lo tatuaban) - los hombres de la cabeza a las rodillas y las mujeres del pecho a las caderas- (Fig. 5). ${ }^{105}$ La cara estilizada grabada en una vasija desenterrada en Campo Grande en el norte de la región en una excavación del año 1981 y la de una vasija excavada en El Abasto en la misma expedición, tienen líneas grabadas en cada

\footnotetext{
${ }^{103}$ Knogler, 1979: "He visto un tribu [cuyos mujeres] se cortan el cabello al rape y dejan solamente una especie de copete desde la frente hasta la coronilla, de la altura del ancho de una mano."

${ }^{104}$ Ibid.: 140-141.

${ }^{105}$ Schmidel, 1903: cap XXXVI.
}

66 Kate Ford. "Hijos de los jesuitas” o ¿Hijos de su propio pasado?... 47-79. 
mejilla que tal vez retraten cicatrices keloidales, tatuajes o pinturas faciales (Fig. 6 y 7). El misionero José Sánchez Labrador dio un informe detallado de las prácticas relacionadas al adorno de la piel de los guarayos del este. Le causó gracia que la gente se sintiera perpleja al ver a los jesuitas sin pinturas. ${ }^{106}$ Él no sabía que cuando estaban "tirando líneas sobre sus cuerpos", ${ }^{107}$ los guarayos tomaban medidas para asegurar su sobrevivencia, según sus creencias; le habría parecido un absurdo la preocupación de los guarayos que por no hacer lo mismo los jesuitas se quedaran expuestos al ataque de espíritus malignos. Los ayoréodes del sureste de la región, hombres y mujeres, frotaban una piedra roja contra otra para tener un pigmento rojo; también usaban hollín, cada color mezclado con saliva antes de ser aplicado al cuerpo. ${ }^{108}$ Las costumbres que el P. Knogler atribuyó a "los chiquitos" en su Relato incluyeron prácticas del adorno del cuerpo de las etnias colindantes, todas con la etnicidad impuesta de chiquita una vez que llegaron a una misión. Sin duda habría sido influido por las escrituras de los PP. Burgés y Fernández, pero hay que señalar que sirvió en Santa Ana en el este de la zona, muy lejos de los primeros pueblos reseñados por estos cronistas. Escribió que hombres "chiquitos":

"se ungen con tierra rodena, embadurnándose especialmente la cabeza, de modo que parecen llevar puesto un casco de punta. Otros se pintan el cuerpo haciendo rayas con materias colorantes extraídas de raíces y plantas. Como la pintura es fácil de quitar, pueden adornarse con otras figuras usando diferentes colores". 109

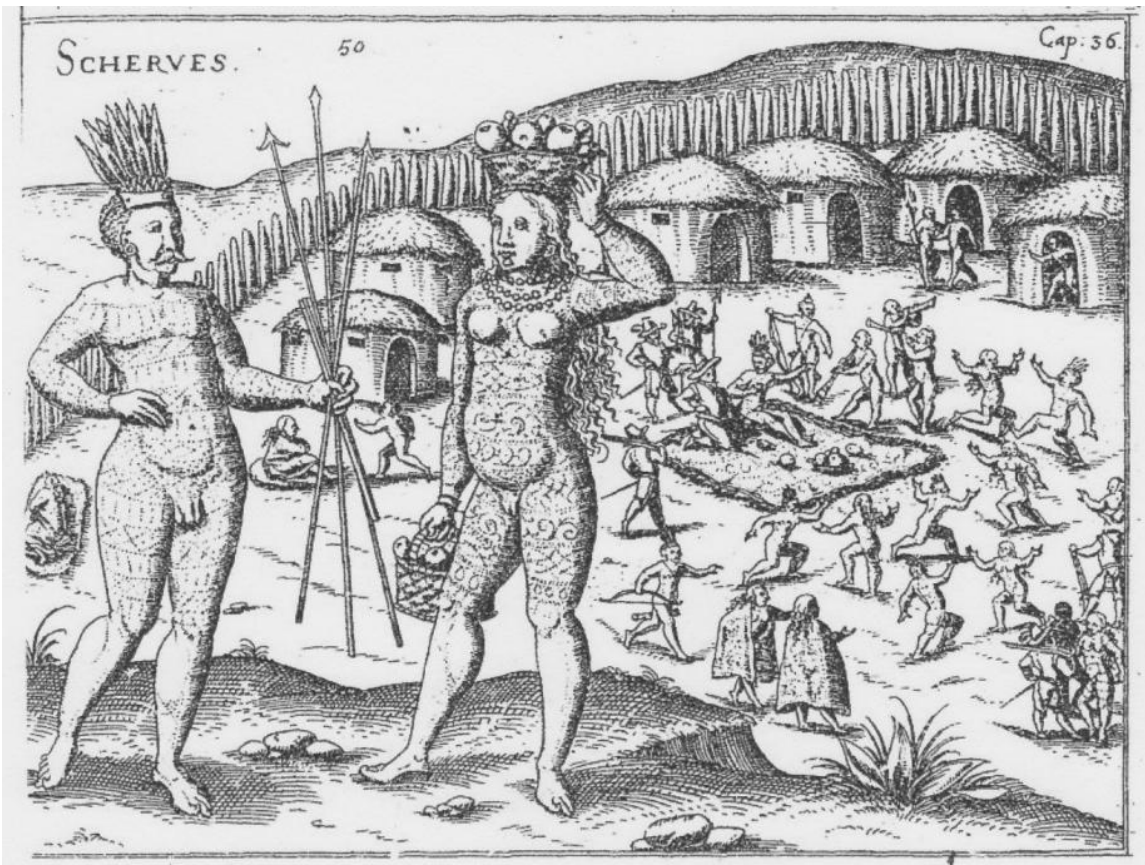

Fig. 5 Grabado no del natural de un hombre y una mujer xarayos publicado en Schmidel, Ulrich Viaje al Río de la Plata 1534-1554 (foto: Tucker, s/f: 45).

\footnotetext{
${ }^{106}$ Sánchez Labrador, 1910: 287.

${ }^{107}$ Ibid.: 286.

${ }^{108}$ Bórmida y Califano, 2003: 91-93.

${ }^{109}$ Knogler, 1979: 140.
} 
Para las mujeres el adorno fue permanente:

"Las mujeres se tatúan sirviéndose de espinas puntiagudas con las cuales se pintan en el rostro una estrella, una flor, un pájaro o un animal; mientras las punzadas están todavía frescas, pulverizan un pedazo de carbón e introducen el polvo en las heridas que forman los contornas de la figura. Cuando las lesiones se han cicatrizado queda este cuadro imborrable, pues nada logra borrar las manchitas negras". 110

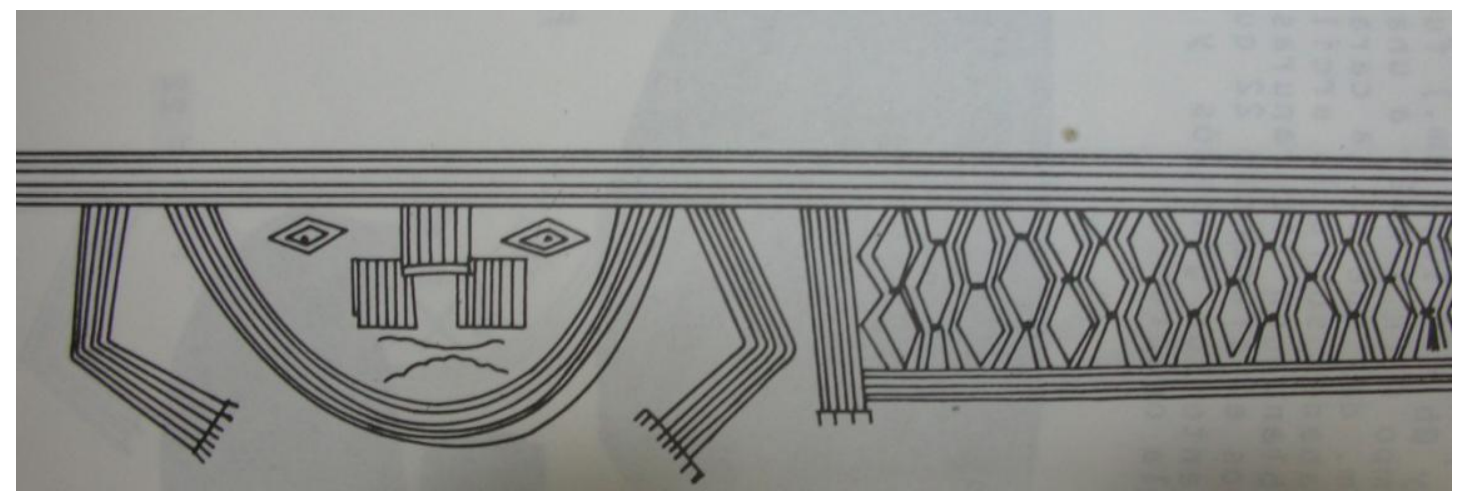

Fig. 6 Bosquejo esquemático de un rostro y formas romboidales grabadas en una vasija desenterrada en Campo Grande (foto: Riester, 1981: 73).

Al mencionarlas en combinación con pájaros, flores y animales, el P. Knogler estuvo diciendo a sus lectores que estas figuras tatuadas en las caras de las "chiquitas" se parecían algo que un europeo habría descrito como una estrella -es decir, una forma de cinco o seis puntas-. Una figura puntiaguda es una fórmula taquigráfica para dibujar una estrella que reconoce el efecto de luz refractada en la retina del observador. Es más probable que el diseño geométrico que Knogler leyó como "estrella" fue, de hecho, un diseño que representó algo más, como, igualmente, tenían que ser los "pájaros", "flores" y "animales". Tal vez la maestría de la tatuadora habría resultado en variaciones menores, pero la figura básica y la razón para que una u otra se hubiera aplicado en cierta parte de la cara no se debía nada al gusto de las protagonistas, sino a la costumbre, y es difícil imaginar que los indígenas pudieran explicárselo a los misioneros, pues tal vez, los indígenas mismos no sabían la razón de esta práctica. El misionero Martín Dobrizhoeffer de la misión de los Abipones del Chaco describió rituales intricados sobre el tatuaje entre los abipones antes de terminar con la siguiente declaración:

"No puedo explicar lo que significan estas figuras, ni lo que presagian, y los abipones mismos tampoco saben mucho del tema. Sólo saben que sus antepasados les transmitieron la costumbre; eso es bastante para ellos". ${ }^{111}$

Desde el punto de vista indígena (un punto de vista que es muy poco probable que fuera explicado a los extranjeros), al modificar el aspecto del cuerpo lo hizo más poderoso, lo alineó a un grupo societal y lo levantó a una zona de contacto a lo so-

\footnotetext{
${ }^{110}$ Ibid.: 140 .

${ }^{111}$ Dobrizhoeffer, 1822: 19-20 "What these figures signify, and what they portend I cannot tell, and the Abipones themselves are no better informed on the subject. They only know that this custom was handed down to them from their ancestors, and that is sufficient."
} 
brenatural. Los métodos para alcanzar a estos estados eran tatuar, pintar, agujerear o escarificar el cuerpo. El cuerpo modificado fue protegido contra los espíritus malos; además tenía algo de sus poderes, por medio de la combinación de la efusión de sangre, los componentes usados para mojar y fijar los pigmentos, y la iconografía misma. ${ }^{112}$ Los jesuitas tenían sus razones para disfrazar los templos y, bajo la autoridad de la Iglesia, los chiquitos los pintaron en una manera que hizo eco de la tradición de la modificación del cuerpo. Así es que, lo que se puede ver en el acto de pintar las paredes es que ambas partes estaban resueltas a representar los conceptos de estatus y protección. Mostró estos conceptos en dos idiomas, cado uno incomprensible a los protagonistas de la otra parte. Fue una casualidad que el acto de pintar trascendió las diferencias culturales.

\subsection{Lo numinoso del templo}

Hay semejanzas iconográficas llamativas en las marcas en el cuerpo indígena descritas por los jesuitas y en las paredes de una iglesia a las marcas grabadas en el barro cocido de las vasijas desenterradas durante las excavaciones arqueológicas, tanto en la región de la misión como en las regiones de donde salió gente para vivir en un pueblo misional. La mayor parte de estas semejanzas tratan de rombos (Fig. 6) y de líneas volutas (Fig. 7). ${ }^{113}$ Esto indica una lengua visual extensamente entendida de símbolos extraídos de la naturaleza para representar la identidad, las creencias y, tal vez, una narrativa del paso, en una variedad de superficies ya sea en la piel de los vivos o en el barro de las vasijas mortuarias. De igual importancia es la inscripción de marcas elocuentes de las culturas regionales en las lajas o las paredes rocosas de la zona de captación de la misión. Los sitios rupestres bolivianos se encuentran o en lugares escondidos o en lugares abiertos que tienen semblanza a un anfiteatro; ${ }^{114}$ en ambos casos se puede reconocer una calidad numinosa. ${ }^{115}$ Mientras que sea difícil llegar a los sitios, no hay duda que son conocidos por los lugareños. Aparte de las vasijas citadas arriba (y hay más), no hay evidencia pictórica del tipo de marcas hechas en cuerpos en la Chiquitania, pero a los chiquitanos y los ayoréodes de hoy las marcas hechas en la roca les dan un enlace visible a sus antepasados.

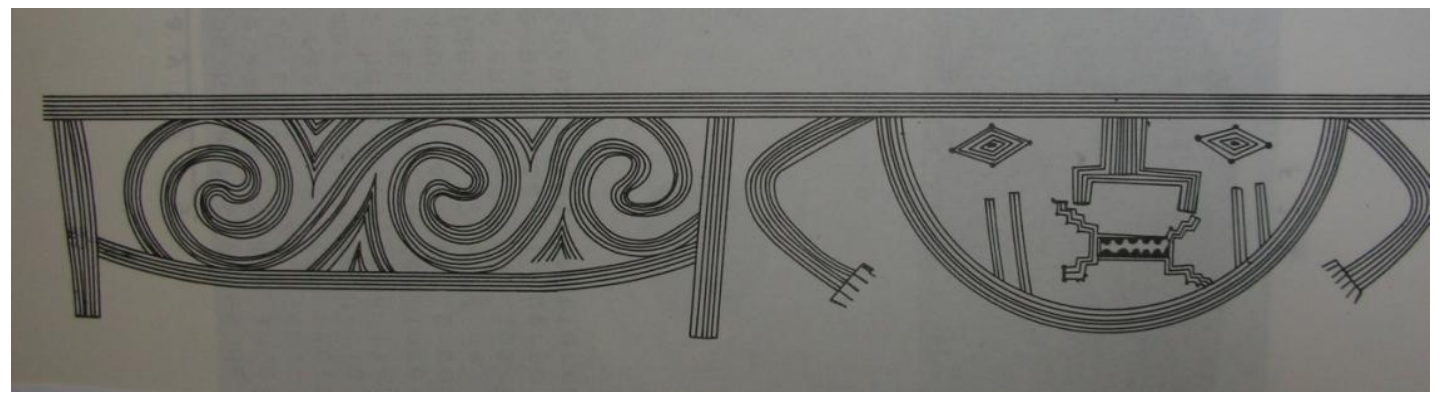

Fig. 7 Bosquejo esquemático de un rostro y líneas cursivas grabadas en la tapa de una urna funeraria desenterrada en El Abasto (foto: Riester, 1981: 50).

\footnotetext{
${ }^{112}$ Karsten, 1968: 188-189.

${ }^{113}$ Riester, 1981: passim.

${ }^{114}$ Conversación con Matthias Strecker de la SIARB, 1.2.11.

115 Matthias Strecker define estos lugares como sitios donde los expertos realizaban ritos (conversación, 1.2.11).
}

69 Kate Ford. "Hijos de los jesuitas” o ¿Hijos de su propio pasado?... 47-79. 
El investigador de arte rupestre Karl Kaifler recuerda que, una vez que dio a entender a la gente chiquitana o ayoréode su interés en las marcas durante su estadía en San José de Chiquitos en los años 1970, ellos le revelaron el paradero de más y más sitios. Sus acompañantes se alegraron de que hubieran sitios de pinturas y petroglifos; le dijeron que no entendieron las marcas mismas, sólo que las marcas trataban de los antepasados ${ }^{116}$-al recordar las palabras de Dobrizhoeffer citadas previamente-

El motivo más obvio, común en la piedra y en los templos, es el rombo. Sirva de ejemplo "los motivos en forma de red y de rombos que en parte cubren una superficie de 5 x 2.50m" del sitio investigado por Riester en 1981, en la Serranía de Santiago (Fig. 8). ${ }^{117}$ Investigaciones subsiguientes de unos sitios rupestres del Oriente señalan que la representación de motivos geométricos repetidos tal vez haya tenido un significado cultural cuando fueron hechos, al tratar de que la repetición tuviera la misma importancia que la figura. Un detalle de la iconografía misional es la presencia de frisos romboidales a lo largo de los pasadizos. Kühne registra el uso de las plantillas para marcar rombos en las paredes de los templos del P. Martín Schmid: la duplicación del motivo articuló los espacios diferentes en el edificio, mientras que la unidad artística fuera afirmada. ${ }^{118}$ La práctica fue reempleada por los restauradores (Fig. 9). Obviamente no podemos hablar de la unidad artística de los motivos rupestres, debido a nuestro desconocimiento de la función de las marcas, pero con respeto al probable carácter sagrado de los sitios, lo que sí podemos asumir es que las ceremonias eran dirigidas por chamanes y, dada su ubicación subamazónica, podemos hacer una conjetura sobre el uso ritual de alucinógenos. Querejazu Lewis cita un pasaje de Clottes y Lewis-Williams sobre el trance producido por drogas:

"En el primer estadio de trance, el más ligero, se "ven" formas geométricas tales como puntos, zigzags, enrejados, conjuntos de líneas o curvas paralelas y meandros. Estas formas tienen colores vivos, centellean, se mueven, se ensanchan, se contraen y se mezclan". 119

No sería de extrañar que estas visiones psicodélicas hubieran animado las marcas hechas en la roca. Calla Maldonado, al escribir de la Cueva de Juan Miserandino cerca de Santiago de Chiquitos, concluye:

"Los modelos shamánicos de interpretación de las representaciones rupestres están relacionados a las experiencias etnográficas; en este sentido las practicas shamánicas y la experimentación con plantas alucinógenas son un tema con ejemplos en grupos actuales de tierras bajas. Por ahora los modelos shamánicos tienen muchas críticas en especial por ser un modelo generalizador pero la posibilidad de explicación de algunos elementos de los contextos

\footnotetext{
${ }^{116}$ Conversación con Karl Kaifler, 7.3.14.

${ }^{117}$ Riester, 1981: 175.

118 Kühne, 2008: 148. "Die Malerei beschränkte sich ganz auf die Betonung der Kanten der Architektur und auf einfache geometrische Motive, die mit Hilfe von Schablonen aufgemalt wurden. Indem Schmid aber die stets gleichen Elemente ganz unterschiedlich einsetze, konnte er die Räume nach ihrer Bedeutung differenzieren und zugleich die Einheit des Gebäudes betonen."

${ }^{119}$ Querejazu Lewis, 2001: 112-113 (paráfrasis del original, Clottes and Lewis-Williams, 1996: 11-30).
} 
está abierta por la gran cantidad de motivos icónicos de sentido polisémico". 120

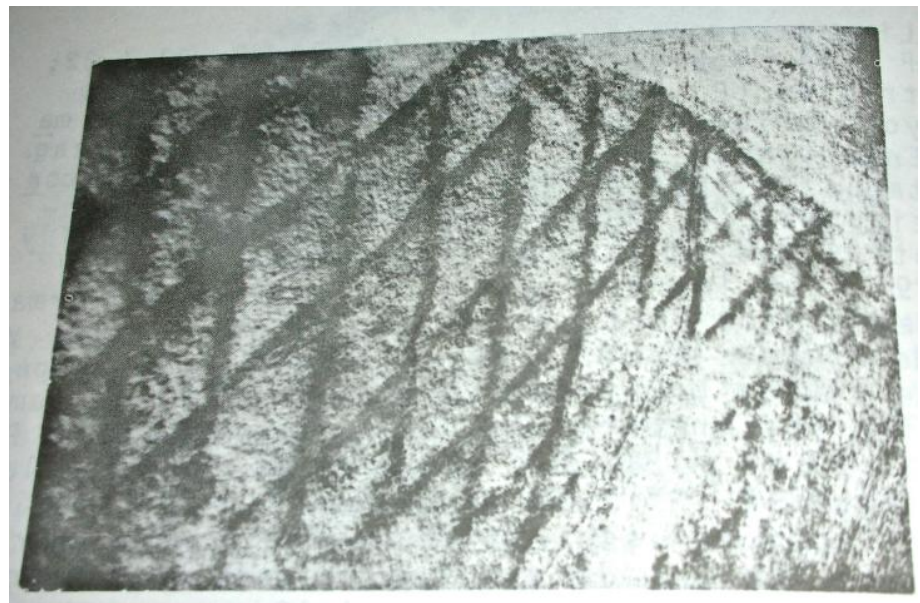

Fig. 8 Pintura rupestre en la forma de una reja romboidal en una pared rocosa entre Santiago de Chiquitos y Roboré (foto: Riester, 1981: 176).
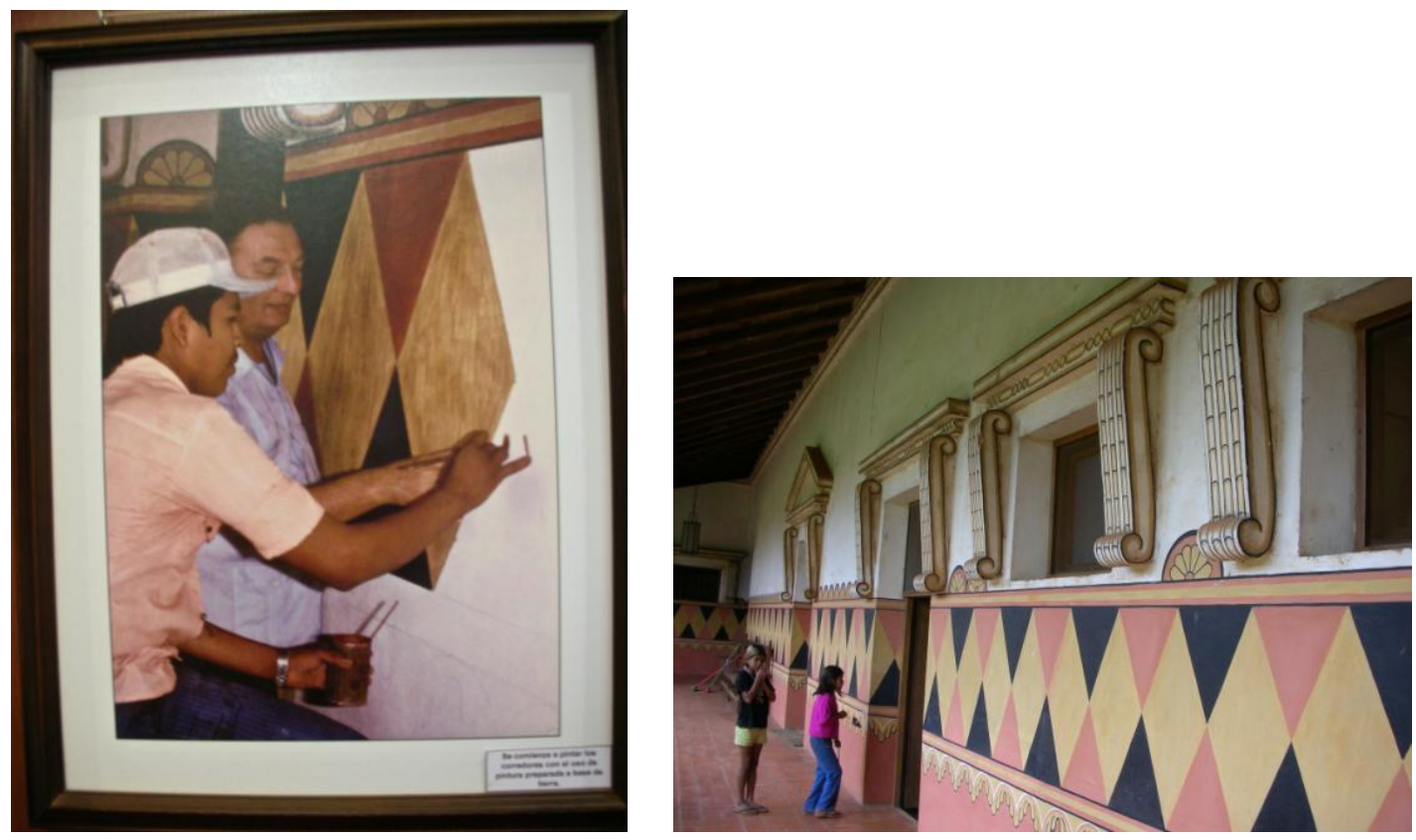

Fig. 9 (a la izquierda) Foto exponido en el Museo de la Catedral, Concepción, en 2010, de un artesano pintando romboides en una pared durante la restauración del conjunto misional, Concepción. La leyenda es "Se comienza a pintar los corredores con el uso de pintura preparada a base de tierra"; (a la derecha) el claustro, Concepción (fotos: la autora, 2010 y 2008).

Si en efecto las sustancias alucinógenas jugaban una parte en el acto ritual de marcar piedra antes de la llegada de los europeos, la documentación de los jesuitas del uso de un líquido negro ceremonial por parte de los maponos manasicos y curan-

${ }^{120}$ Calla Maldonado, 2007: 23. 
deros chiquitos nos muestra una conexión entre la época de las marcas y la época de la Misión. Tanto los PP. Burgés como Caballero registraron "una materia negra",121 o "sangre, que de ordinario ven negra" "122 como parte del tratamiento de los enfermos, y Caballero mencionó la unción de un candidato al sacerdocio con el vómito negro del mapono anciano. ${ }^{123}$ Para él, la declaración de que los maponos volaban pareció una mentira cínica inventada para causar una impresión en la gente. De hecho ¿creían realmente que "volaban" de veras? estimulados por una droga psicotrópica, hervida hasta que se volvió negra.

Fernández describió fieras cooptadas en la fiesta de Corpus Cristi en la Misión:

"y a fin de que todas las criaturas, aún irracionales, rindan homenaje y tributo de reverencia al común señor de todas, salen días antes a caza de pájaros y de fieras, aunque sean tigres y leones, y bien atados los ponen en el camino por donde ha de pasar el Santísimo Sacramento". 124

Cualquier felino que fuera, debió haber sido drogado, tal vez con tabaco crudo polverizado. ${ }^{125}$ El uso del tabaco crudo como estupefaciente en el área de la misión fue registrado posteriormente como parte de los ritos de la iniciación de un chamán ayoreo. ${ }^{126}$ Los chiquitos de antaño usaban barbasco para aturdir a los pescados, conscientes de que la planta afectaría solo a criaturas de sangre fría y por lo tanto sería inocua para los que la comieran. ${ }^{127}$ Las puntas de sus flechas eran envenenadas, como nos dicen Knogler y Dobrizhoeffer. ${ }^{128}$ Evidentemente había un conocimiento complejo de sustancias tóxicas, algo que a mí me lleva a pensar que el uso de alucinógenos por una clase élite sacerdotal existía en la región antes de la llegada de catolicismo. ${ }^{129}$

\footnotetext{
${ }^{121}$ Burgés, 2008: 90.

${ }^{122}$ Caballero, 1933: 29

${ }^{123}$ Ibid.: 29-30.

${ }^{124}$ Fernández, 1994: 75.

${ }^{125}$ Wake, 2010: 72. Menciona un cuadro vivo del año 1538 en Tlaxcala en México que incluyó pájaros, animales y culebres vivos, "algunos muy venenosos que se hicieron inertes con picietl [tabaco crudo polverizado]" ("some extremely venemous but made sluggish with picietl [powdered raw tabacco]").

${ }^{126}$ Bórmida y Califano, 2003: 311.

${ }^{127}$ Knogler, 1979: 133. APCOB, 2006: 179. El nombre botánico de la trepadura barbasco es Lonchocarpus nicou, y Tephrosia sinapou también contiene rotenone, el elemento estupefactante, en su raíz (Kamen-Kaye, 1977: 71-90).

${ }^{128}$ Knogler, 1979: 142. "También suelen envenenar sus flechas, de modo que ya una pequeña herida sangrante es absolutamente incurable; el curare que usan es un secreto que solamente algunos viejos conocen." Curare afloja los músculos y impide la capacidad de respirar. Dobrizhoeffer escribió de las flechas de los chiquitos que se las mojaban en el veneno de un "árbol desconocido" que infectó la sangre, hizo que se hicharan las extremidades y resultó en la muerte dentro de pocas horas (Dobrizhoeffer, 1822: 355). Se hace curare por hervir en combinación la corteza de Strychnos toxifera o Strychnos guianensis (fam.Loganiaceae) y Chododendron tormentosum o Sciadotenia toxifera (fam.Menispermaceae) (http://www.botgard.ucla/html/botanytextbooks/economicbotany/index.html, 16.4.11).

${ }^{129}$ La "materia negra" hubiera sido Echinopsis, o una mezcla de Nicotiana rustica y Brosimum acutifolium - cualquiera de los dos llegaría al olor de "goma" anotado por Caballero cuando describió el ritual manasica. (Caballero, 1933: 29-30).
} 
No podría haber pasado inadvertido a los indígenas que el sacerdote jesuita era el único que tomaba el vino de la eucaristía. Caballero nos informa en su Relación del papel intrínseco del chamán como mediador entre la gente manasica y el mundo de lo sobrenatural. El papel mediador de un sacerdote jesuita era idéntico. Un pasaje de la Relación describe un encuentro entre un mapono manasica acompañado por su comitiva, y una deidad manasica: "hablando con el principal, los hechiseros [sic] y chupadores le disen [sic] seas bien venido padre tata; le llaman, y aún a mí suelan llamar con el mismo nombre" $"$.

Caballero describió los numerosos deberes del mapono de una manera que prefigura la famosa descripción del P. Schmid de un misionero multifacético. ${ }^{131} \mathrm{Ca}$ ballero le describe como "el Mago, el sacerdote de los dioses, el Doctor de la Ley, y a quien consultan sus dudas y necesidades en el Pueblo". " ¿Cómo fuera posible que los neófitos (y, seguramente, sus niños y nietos criados con los cuentos de una vida previa) no asociaran los oficios de sacerdote jesuita y mapono? Y, por eso, ¿qué le parecería más natural a la gente con el "folk memory" ver a los chamanes marcando sitios de significado místico que un sacerdote/arquitecto jesuita tomando una tiza o un pincel cargado de pintura de color de las figuras dibujadas en la piedra (o mandando hacer lo mismo a otra persona) para enfatizar la importancia de este sitio místico nuevo? Y, en ese caso, ¿no sería obvio para ellos que lo que el sacerdote les mandara a dibujar hubiera sido las formas geométricas de rombos (fortuitamente semejantes a la geometría barroca de suelos embaldosados y techos o paredes artesonados) que encuadraban experiencias sobrenaturales "documentadas" en la pared rocosa por los chamanes de antaño?

\section{Conclusión}

Se puede describir los sitios rupestres como textos de la experiencia de ser indígena, y también como palimpsestos de esa identidad (debido a los sobre-dibujos visibles en unos sitios). Sostengo que la iglesia de una misión jugaba un papel igual. Hay un complejo "multi-layering" de culturas en su arquitectura - un "maquillaje" barroco encima de un edificio indígena -, en su adorno que empleaba una fusión de la iconografía europea y el recuerdo indígena y, tal vez, incluso en su atrio sobresaliente haciendo eco de los abrigos que han protegido las paredes rocosas decoradas de las depredaciones del clima hace siglos. El emplazamiento de un templo misional tenía en cuenta la autoridad jesuítica, mandada de afuera, y criterios prácticos -tierra plana, árboles cercas para ser talados, y orientación (aunque fuera variable)-. Los templos misionales que sobrevivieron hasta la restauración fueron construidos por los descendientes de los primeros conversos, no por los primeros conversos mismos. Pero no debemos ignorar la sobrevivencia de costumbres indígenas en la misión, algo que arrepintiéndose admitían los misioneros. Lo que uno podría considerar había sido borrado después del fallecimiento de una generación continuó en la mente de las ge-

\footnotetext{
${ }^{130}$ Caballero, 1933: 23.

${ }^{131}$ Schmid, 1993: 138. "Así [los jesuítas] son consejeros y jueces, médicos y cirujanos, son albañiles, carpinteros y ebanisteros, son herreros, cerrajeros, sastres, zapateros, molineros, panaderos, cocineros, pastores, jardineros, pintores, escultores, torneros, carroceros, ladrilleros, alfareros, tejedores, curtidores, caraceros [¿cereros?], calderos, estañeros y lo que se necesita de artesanos en una comunidad ordenada."

${ }^{132}$ Caballero, 1933: 31.
} 
neraciones posteriores, junto con su fe cristiana meramente "nominal". Si los chiquitanos del tercer cuarto del siglo XX se adhirieron a sus creencias antiguas (como nos muestran los estudios antropológicos de Riester, Strack, Fischerman y Balza Alarcón), es razonable asumir que los "chiquitos" misionales del siglo XVIII hicieran lo mismo. Sostengo que una vez erigido, pintado y consagrado, el edificio físico mismo, además de encarnar lo sagrado, representaba lo sagrado a los chiquitos en la misma manera que se les había representado un sitio sagrado de antaño a sus padres y abuelos.

No hay duda que una sensación realzada de lo real, intensificada por la emoción de los participantes, llenaba a los fieles, como describió Martín Schmid en una carta a su hermano de 1744:

"El resultado de estos esfuerzos en gobernar las almas es asombroso: las alfombras que cubren el piso de las iglesias quedan mojadas con las lágrimas de los penitentes, el recinto resuena con sus suspiros y la plática es interrumpida varias veces por una vehemente autoflagelación de los oyentes". ${ }^{133}$

En términos modernos se hablaría de la histeria de un grupo, inducida por el tamaño y el esplendor del edificio, la calidad cautivadora de la liturgia y la música y, tal vez, por un elemento de la piedad competitiva. Empero, en mi opinión, en el período misional la emoción de la feligresía se debió al edificio mismo, construido en un estilo autóctono, adornado en un estilo autóctono y que reflejaba las creencias autóctonas.

La casa del nuevo Dios -un "cuerpo" que necesitó protección como también un lugar sacro- fue ornamentada en un estilo que relató una narrativa indígena de identidad por métodos que simultáneamente fortalecieron el templo y lo protegieron en el pensamiento indígena. Es meramente una coincidencia que la cultura europea y la de los indígenas del Oriente compartieran ciertos elementos gráficos. Lo fortuito para los protagonistas fue que el uso decorativo de estos elementos gráficos en los templos revivía un recuerdo atávico indígena de un ritual litúrgico dirigido por una figura autoritaria en un sitio de asociaciones sobrenaturales, al mismo tiempo que el uso de marcas para proteger, fortalecer e identificar el cuerpo humano todavía predominaba.

\section{Bibliografía}

Apoyo para el Campesino-Indígena del Oriente Boliviano (APCOB) (ed) (2006). Saberes del Pueblo Chiquitano, Santa Cruz de la Sierra: Ministerio de Educación, Dirección Nacional de Educación Intercultural Bilingüe, Programa Amazónica de Educación Intercultural Bilingüe.

Balza Alarcón, Roberto (2001). Tierra, Territorio y Territorialidad Indígena: un estudio antropológico sobre la evolución en las formas de ocupación del espacio del pueblo indígena chiquitano de la ex-reducción jesuita de San José, Santa Cruz de la Sierra: APCOB/SNV/IWGIA Serie de Pueblos Indígenas de las Tierras Bajas de Bolivia, 17.

\footnotetext{
${ }^{133}$ Schmid, 1979: 141.
} 
Birk, Gudrun (trans Shand, Alexandra) (2000). Dueños del bosque/Owners of the forest: Manejo de los recursos naturales por indígenas chiquitanos de Bolivia, Santa Cruz de la Sierra: APCOB-CICOL, Serie de Pueblos Indígenas de las Tierras Bajas de Bolivia, 14.

Bórmida, Marcelo y Califano, Mario (2003). 'Los Ayoreo del Chaco Boreal' in Zanardini, José (ed) Cultura del Pueblo Ayoreo, Asunción: CEADUC.

Bösl, Antonio Eduardo, ofm (1989). Una Joya en la Selva Boliviana, Bolivia: Vicariato Apostólico de Nuflo de Chávez.

http://www.botgard.ucla/html/botanytextbooks/economicbotany/index.html [curare].

Brabo, Francisco Javier (1872). Inventarios de los bienes hallados a la expulsión de los jesuíticas y ocupación de sus temporalidades por decreto de Carlos III en los pueblos de misiones, fundados en las márgenes del Uruguay y Paraná, en el Gran Chaco, en el país de Chiquitos y en el Mojos, Madrid: Imp y Esterotipia de W Rivadeneyra.

Brotherston, Gordon (1979). Image of the New World: The American continent portrayed in native texts, London: Thames and Hudson.

Brotherston, Gordon (1992). Book of the Fourth World, Cambridge: Cambridge University Press.

Burgés, Francisco SJ (1703). Memorial al Rey Nuestro Señor en su Real, y Supremo Consejo de las Indias sobre las Noticias de las Misiones de los Indios llamadaos Chiquitos in Tomichá Charupá, Roberto OFM Conv (2008) Francisco Burgés y las Misiones de Chiquitos: El Memorial de 1703 y documentos complementarios, Cochabamba: Instituto Latinoamericano de Misionología.

Caballero, Lucas (1933) [1706]. Relación de las costumbres y religión de los indios manasicas, Madrid: Librería General de Victoriano Suárez.

Caballero, Lucas (1707-1708). "Diario de la cuarta misión a los manasicas y paunacas" in Matienzo, Javier, Tomichá, Roberto, Combès, Isabelle, Page, Carlos (eds) (2011). Chiquitos en las Anuas de la Compañía de Jesús (1691-1767), Cochabamba: Itinerarios Editorial, pp.46-83.

Calla Maldonado, Sergio (2007). "Documentación de las Pinturas de la Cueva de Juan Miserandino, Reserva Municipal del Valle de Tucavaca, Depto. de Santa Cruz", Sociedad de Investigación del Arte Rupestre de Bolivia (SIARB) Boletín 21, La Paz, pp.17-37.

Clottes, Jean and Lewis-Williams, David (palabras de Clottes trad Hawkes Sophie) (1998 [Paris, 1996]). The Shamans of Prehistory: trance and magic in the painted caves, New York: Harry N. Abrams.

Combès, Isabelle (2009). Zamucos, Cochabamba: Instituto de Misionología, Colección Scripta Autochtona, 1.

Combès, Isabelle (2010). Diccionario Étnico: Santa Cruz la Vieja y su Entorno en el Siglo XVI, Cochabamba: Itinerarios/Instituto Latinoamericano de Misionología. 
Cunninghame Graham, R B (1924) [1901]. A Vanished Arcadia, being Some Account of the Jesuits in Paraguay, 1607 to 1767, London: Heinemann.

Diez Gálvez, María José (2006). Los bienes muebles de Chiquitos: Fuentes para el conocimiento de una sociedad, Madrid: Agencia Española de Cooperación Internacional, Dirección General de Relaciones Culturales y Científicas.

Dobrizhoeffer, Martin (trad Coleridge, Sara) (1822). An Account of the Abipones: an equestrian people of Paraguay, vol 2 (of 3), London: John Murray.

Durkheim, Émile y Mauss, Marcel (trad Needham, Rodney) (1963) [1903]. Primitive Classification, London: Cohen \& West.

Fernández, Juan Patricio SJ (Introducción y notas por Santamaría, Daniel J.) (1994) [1726]. Relación Historial de las misiones de indios Chiquitos que en el Paraguay tienen los padres de la Compañía de Jesús, San Salvador de Jujuy: Centro de Estudios Indígenas y Coloniales, Departamento Editorial, Biblioteca de Historia y Antropología/2.

Fischerman, Bernd (1995). 'Camba-Paico: La Chiquitanía en la época republicana' in Querejazu, Pedro (ed) Las Misiones Jesuíticas de Chiquitos, La Paz: Fundación BHN, Línea Editorial.

Fischermann, Bernd and Quiroaga, Rosa María (1996). 'Viviendo en el bosque' en el periódico cruceño El Deber (Sección cultural) 21.9.96, pp.3-5.

Fitzpatrick, P. J. (1993). In Breaking of Bread: The Eucharist and Ritual, Cambridge: Cambridge University Press.

Fraser, Valerie (1982). 'Hierarchies and Roles of Materials in Building and Representation', pp.41-56 en Fraser, Valerie y Brotherston, Gordon (eds) The Other America: Native Artifacts from the New World, Essex (para la exposición Native Artifacts of the New World, Museum of Mankind, London: University of Essex.

Fraser, Valerie (1990). The Architecture of Conquest: Building in the Viceroyalty of Peru 1535-1635, Cambridge: Cambridge Iberian and Latin American Studies.

Freyer, Bärbel (2000). Los Chiquitanos: Descripción de un pueblo de las tierras bajas orientales de Bolivia según fuentes jesuíticas del siglo XVIII, Santa Cruz de la Sierra: APCOB, Serie de Pueblos Indígenas de las Tierras Bajas de Bolivia, 15.

Galeote Tormo, Jesús (1996). Manityana auki besiro: Gramática moderna de la Lengua Chiquitana y vocabulario básico, Santa Cruz de la Sierra: Imprenta "Los Huérfanos".

Gell, Alfred (1992). 'The Technology of Enchantment and the Enchantment of Technology', en Coote, Jeremy and Skelton, Anthony (eds) Anthropology, Art and Aesthetics, Oxford: Oxford Studies in Social and Cultural Anthropology, pp.40-63.

Groesbeck, Geoffrey A. P. (2012). 'Evanescence and Permanence: Toward an Accurate Understanding of the Legacy of the Jesuit Missions of Chiquitos', www.LaGranChiquitania.com [publicado inicialmente con título diferente en University of Illinois Journal of Bolivian Studies, 2009]. 
Hoffmann, Werner (1979). Las Misiones Jesuíticas entre los Chiquitanos, Buenos Aires: Fundación para la Educación, la Ciencia y la Cultura [contiene Knogler, Julian, SJ Relato sobre el pais y la nación de los chiquitos en las Indias occidentales o América del sud y las misiones en su territorio, redactado para un amigo].

Hoffmann, Werner (1981). Vida y obra del P. Martin Schmid SJ (1694-1772), Buenos Aires: Fundación para la Educación, la Ciencia y la Cultura [contiene unas cartas de Schmid].

Hubert, H and Mauss, M (trad Warschaver, Eduardo) (1946). Magia y Sacrificio en la Historia de las Religiones, Buenos Aires: Editorial Lautaro.

Kaifler, Carlos (1993). "Tres Sitios de Pinturas Rupestres en la Parte Occidental de la Serranía San José, Depto. de Santa Cruz, Bolivia”, SIARB Boletín 7, La Paz, pp.59-95.

Kamen-Kaye, Dorothy (1977). "Ichthyotoxic plants and the term 'barbasco"', Botanical Museum Leaflets, Harvard University, vol 25, no 2, pp.71-90.

Karsten, Rafael (1968) [1926]. Civilization of the South American Indians With Special Reference to Magic and Religion, London: Dawsons.

Knogler, Julian SJ (1767-1772). Relato sobre el país y la nación de los chiquitos en las Indias occidentales o América del sud y las misiones en su territorio, redactado para un amigo. In Hoffmann, Werner (1979) Las Misiones Jesuíticas entre los Chiquitanos, Buenos Aires: FECIC.

Kranianskas, John (1998). "Cronos and the political economy of vampirism: notes on a historical constellation". In Barker, Francis, Hulme, Peter y Iverson, Margaret (eds). Cannibalism and the Colonial World, Cambridge: Cambridge University Press, pp.142-157.

Krekeler, Birgit (1993). Historia de los Chiquitanos, Santa Cruz de la Sierra: AP$\mathrm{COB}$, Serie de Pueblos Indígenas de las Tierras Bajas de Bolivia, 2.

Kühne, Eckart (2008). Die Missionskirchen von Chiquitos im Tiefland von Bolivien: Bau und Restaurierung der Kirchen von Martin Schmid (1694-1772), Zürich: tesis doctoral inédito, ETH Zürich.

Matienzo, Javier, Tomichá, Roberto, Combès, Isabelle, Page, Carlos (eds) (2011). Chiquitos en las Anuas de la Compañía de Jesús (1691-1767), Cochabamba: Instituto de Misionología, Colección Scripta Autochtona, 6.

Menacho, Antonio (1996). Por Tierras de Chiquitos: Los Juesuitas en Santa Cruz y en las Misiones de Chiquitos en los Siglos 16 a 18, Bolivia: Vicariato Apostólico de Nuflo de Chávez.

Parejas Moreno, Alcides y Suárez Salas, Virgilio (1992). Chiquitos: Historia de una Utopía, Bolivia: Cordecruz, Universidad Privada de Santa Cruz de la Sierra

Querejazu, Pedro (ed) (1995). Las Misiones Jesuíticas de Chiquitos, La Paz: Fundación BHN, Línea Editorial.

Querejazu, Pedro (2000). "La imaginería en Chiquitos". In APAC III Reunión Cientifica, Bolivia: Asociación Pro Arte y Cultura APAC. 
Querejazu Lewis, Roy (2001). El Arte Rupestre de la Cuenca del Río Mizque, Bolivia: Universidad Mayor de San Simón, Prectura del Departamento de Cochabamba.

Riester, Jürgen (1976). "Los Chiquitanos”. In Riester, Jürgen y Bernd Fischerman, En Busca de la Loma Santa, La Paz, Cochabamba: Editorial Los Amigos del Libro, pp.119-182.

Riester, Juergen G (1981). Arqueología y arte rupestre en el oriente boliviano, Cochabamba: Editorial Los Amigos del Libro.

Riester, Jürgen y Fuss, Max (1986). Zúbaka, La Chiquitanía: visión antropológica de una región en desarrollo, vol 1 [el sólo volumen publicado] Vocabulario del Chiquito, Cochabamba, La Paz: Editorial Los Amigos del Libro.

Roth, Hans (1987). "Lo que entonces sucedió". In Bösl, Antonio Eduardo, ofm Una Joya en la Selva Boliviana, Bolivia: Vicariato Apostólico de Ñuflo de Chávez, pp 15-48.

Roth, Hans (1995). "Urbanismo y Arquitectura en Chiquitos desde los Testimonios Materiales". In Querejazu, Pedro (ed), Las Misiones Jesuíticas de Chiquitos, La Paz: Fundación BHN, Línea Editorial.

Sá, Lúcia (2004). Rainforest Literatures, Minneapolis, London: University of Minnesota Press.

Sánchez Labrador, José, SJ (1910) [c.1770]. El Paraguay Católico, vol 1, Buenos Aires: Coni Hermanos.

Schmid, Martin SJ (1981). Cartas en Hoffmann, Werner (1981) Vida y obra del P. Martin Schmid SJ (1694-1772), Buenos Aires: Fundación para la Educación, la Ciencia y la Cultura.

Schmid, Martin SJ (1993). carta en Krekeler, Birgit (1993), Historia de los Chiquitanos, Santa Cruz de la Sierra: APCOB, Serie de Pueblos Indígenas de las Tierras Bajas de Bolivia, 2.

Schmidel, Ulrich (trad Lafone Quevedo, Samuel) (1903) [1567]. Viaje al Río de la Plata 1534-1554, http://www.cervantesvirtual.com (Buenos Aires: Cabaut \& Cia).

Strack, Peter, con un annexo por Kühne, Eckart (trad del alemán al español, Garrido A, Anneliese, Jaeger, Christa y Kaifler, Karl) (1992). Frente a Dios y los Pozokas, Fiesta Patronal y Semana Santa en Chiquitos: Las tradiciones culturales y sociales de las reducciones jesuíticas desde la conquista hasta el presente, Bielefeld: Verlag für Regionalgeschichte.

Szabó, Henriette Eva (2008). Diccionario de la Antropología boliviana, Bolivia: aguaragüe.

Taussig, Michael (2006). Walter Benjamin's Grave, Chicago, London: University of Chicago Press.

Tomichá Charupá, Roberto OFM Conv (2002). La Primera Evangelización en las Reducciones de Chiquitos, Bolivia (1691-1767): Protagonistas y metodología 
misional, Cochabamba: UCB-OFMC-Verbo Divino, Colección Misión y Diá$\log 3$.

Tomichá Charupá, Roberto OFM Conv (2008). Francisco Burgés y las Misiones de Chiquitos: El Memorial de 1703 y documentos complementarios, Cochabamba: Editorial Verbo Divino, Colección Misión y Diálogo 11.

Tucker, G R (s/f), 'The Discovery of Germany in America: Hans Staden, Ulrich Schmidel, and the Constructin of a German Identity' in University of Texas at Arlington Traversea, Vol 1, www.uta.edu/history/traversea/.../pdf_1.

Turner, Bryan (1996). The Body and Society: Explorations in Social Theory, London, Thousand Oaks, New Delhi: Sage Publications Ltd.

Vaca Céspedes, Damián (2010). Música, Danza e Instrumentos Tradicionales del Departamento de Santa Cruz, Santa Cruz: Fondo Editorial Municipal.

Waisman, Leonardo (2013). "The Singing Demons of San Ignacio: Musical Interfaces between Jesuits and Indians", presentación dado en Columbia University, New York (disponible en Academia.edu).

Wake, Eleanor (2010). Framing the Sacred: The Indian Churches of Early Colonial Mexico, Norman Oklahoma: University of Oklahoma Press. 